\title{
Effect of gas hydrates melting on seafloor slope instability
}

\author{
N. Sultan ${ }^{a^{*}}$, P. Cochonat ${ }^{a}$, J.-P. Foucher ${ }^{a}$ and J. Mienert ${ }^{b}$ \\ aIFREMER Brest, Departement de Geosciences Marines, Technopole de Brest-Iroise B.P. 70 Plouzané F-29280, \\ France \\ ${ }^{\mathrm{b}}$ University of Tromsø, Troms $\varnothing$, Norway \\ *: Corresponding author : Corresponding author. Tel.: +33 29822 42 59; fax: +332 98224570 \\ nabil.sultan@ifremer.fr
}

\begin{abstract}
We present a theoretical study of the thermodynamic chemical equilibrium of gas hydrate in soil by taking into account the influence of temperature, pressure, pore water chemistry, and the mean pore size distribution. The model uses a new formulation based on the enthalpy form of the law of conservation of energy. The developed model shows that due to a temperature and pressure increase, hydrates may dissociate at the top of the hydrate occurrence zone to ensure a chemical equilibrium with the surrounding bulk water. This original result confirms what has been already shown through experiments.

The second part of the paper presents an application of the model through a back-analysis of the giant Storegga Slide on the Norwegian margin. Two of the most important changes during and since the last deglaciation (hydrostatic pressure due to the change of the sea level and the increase of the sea water temperature) were considered in the calculation. Simulation results show that melting of gas hydrate due to the change of the gas solubility can be at the origin of a retrogressive failure initiated at the lower part of the Storegga slope. Once again, the developed model leads to predictions, which are supported by laboratory experiment results, but contradictory to previous interpretations and beliefs considering that hydrate dissociation occurs only at the bottom of the gas hydrate stability zone.
\end{abstract}

Keywords: methane hydrate; finite difference; GLE; slope failure; Storegga 


\section{ABSTRACT}

We present a theoretical study of the thermodynamic chemical equilibrium of gas hydrate in soil by taking into account the influence of temperature, pressure, pore water chemistry and the mean pore size distribution. The model uses a new formulation based on the enthalpy form of the law of conservation of energy. The developed model shows that due to a temperature and pressure increase, hydrates may dissociate at the top of the hydrate occurrence zone in order to ensure a chemical equilibrium with the surrounding bulk water. This original result confirms what has been already shown through experiments.

The second part of the paper presents an application of the model through a back-analysis of the giant Storegga Slide on the Norwegian margin. Two of the most important changes during and since the last deglaciation (hydrostatic pressure due to the change of the sea level and the increase of the sea water temperature) were considered in the calculation. Simulation results show that melting of gas hydrate due to the change of the gas solubility can be at the origin of a retrogressive failure initiated at the lower part of the Storegga slope. Once again, the developed model leads to predictions, which are supported by laboratory experiment results, but contradictory to previous interpretations and beliefs considering that hydrate dissociation occurs only at the bottom of the gas hydrate stability zone.

\section{Keywords: Methane Hydrate, Finite difference, GLE, Slope Failure, Storegga.}

\section{INTRODUCTION}

Gas (usually methane) in marine sediments may be either thermogenic or biogenic. Under intermediate pressure, low temperature, and adequate gas concentrations, gas can occur in the seabed as gas hydrates (solid phase). Natural changes in bottom water temperature and/or in pressure can destabilize hydrate layers, and potentially result in large landslides and soil failures. In addition, human activity on the seafloor (drilling, laying pipe lines) related to the 
petroleum exploration and development in deep water is another source of hydrate dissociation. In order to prevent the risk related to the occurrence of the gas, it is essential to identify the dynamic of the hydrate system and the consequence of its dissociation on the sediment failures and slope instability.

Gas hydrate may at sufficient concentrations cement sediments and significantly modify the sediment strength; its formation and breakdown may influence the occurrence and location of submarine landslides. Several examples from literature show that the upper limit of the gas hydrate stability zone (pinch-out) where expulsion of free gas is expected can lead to weak seabed and can be considered a potential geohazard area. Parameters that affect gas hydrate stability include temperature, pore pressure, gas chemistry, pore-water salinity and pore size distribution. Changes in the equilibrium parameters converting the hydrate to gas plus water, may cause significant weakening of the sediment, and generate a rise in pore pressure. A significant consequence of the hydrate melting is the gas release, which may alter significantly the behaviour and mechanical properties of the marine soils (see for instance Wheeler 1988-a and 1988-b). Gassy soil, which contains relatively large amount of gas dissolved in the pore fluid, is very hazardous when unloaded in undrained conditions and where the pore pressure reaches the liquid/gas saturation pressure (see for instance Sobkowicz and Morgenstern 1984). In addition to the excess pore pressure and gas release generated by the hydrate melting, the presence of gas hydrate, which cements the grains together and/or filled the voids, may prevents the normal sediment compaction processes in the gas hydrate stability zone. In this case hydrate dissociation may generate an under-consolidated soil with a significant weakening of the soil resistance.

An accurate approach to evaluate the geological risks associated to gas hydrate melting is presented in Figure 1. To our knowledge degradation of the soil resistance due to hydrate melting has not been investigated in the literature and consequently was unfortunately not 
considered accurately in this study. Another limitation in the developed model concerns the mechanical behaviour of gassy soil. The soil was considered as saturated and the constitutive model used to evaluate the slope instability was Mohr-Coulomb.

\section{THERMODYNAMIC-CHEMICAL MODEL FOR GAS HYDRATE PHASE STABILITY}

Quantitative dynamic models of gas hydrate in marine sediments can be grouped into two categories. The fundamental solved equations in the first category are those for conservation of momentum, fluid mass and energy for transient and steady state regime. A first class of these steady-state models takes into account methane conservation, the supply of gas being then considered (Rempel \& Buffett, 1997; 1998; Xu \& Ruppel, 1999). Whereas Rempel \& Buffett (1997) ignore diffusion in fluid phase, Rempel \& Buffett (1998) and Xu \& Ruppel (1999) propose a complete treatment of the gas (methane) advective-diffusive flow coupled with heat transfer. Egeberg \& Dickens (1999) consider the chloride content of the pore fluid, but their model does not take into account the dissolved methane in the pore fluid. Davie \& Buffett (2001) couple both approaches: they simulate the pore fluid chemistry, both in terms of chloride content and dissolved methane in gas and hydrate phases, the methane migration being taken into account either by advection or by diffusion in fluid phase when dissolved. Another line of inquiry deals with models, which are often conceptually simpler: the only solved equation is usually the energy conservation in transient regime. Mienert et al. (2001) work on the modelling of the Hydrate Stability Zone (HSZ) as a function of temperature and pressure. They show a distinct decrease of the HSZ at the Norwegian margin from the last glacial maximum (LGM) to the present time. Briaud \& Chaouch (1997) propose a model of gas hydrate dissociation beneath oil platform due to the heat released around pipes where hot oil travels from the well to the platform. They report that melting process generates a large amount of gas that can endanger the stability of the foundation. Delisle et al. (1998) propose a model of gas hydrate formation due to the thermal re-equilibration occurring after slumps. 
The main result suggests that the structure do not regain complete thermal equilibrium after slumping in the course of several tens of years. Both Briaud \& Chaouch (1997) and Delisle et al. (1998) emphasize that the latent heat greatly impedes gas hydrate formation and dissociation: additional heat source and heat sink are produced as gas hydrate forms and dissociates respectively. By neglecting the effect of gas components and concentration on the gas hydrate stability law, and only considering the energy conservation equation, this second category of models is inadequate by regarding mainly the following three points:

1) The low concentration of gas in the upper meters of sediment, which can be related to the methane exchange between bulk water and seawater column, can prevent the formation of gas-hydrates. Thus, gas-hydrate stability zone from $\mathrm{p}-\mathrm{T}$ conditions does not necessarily coincide with the real hydrate occurrence zone (see for instance Xu \& Ruppel 1999).

2) The hydrate fraction, which depends on the gas concentration and fluxes within the sediment column, is often improperly considered, by the last category of model, as constant. Indeed, to form gas hydrates, gas concentrations must exceed the solubility level at the in-situ pore water conditions. All the volume gas in excess of the solubility is stored in hydrate.

3) The excess pore pressure generated by the melting of the gas hydrate depends on i) the hydrate fraction ii) on the gas solubility and iii) on the medium compressibility. Therefore, by considering only the energy conservation equation and neglecting the gas effect, it is impossible to evaluate the excess pore pressure inside or/and outside the hydrate stability zone.

Therefore, in this paper, a numerical model of the formation or dissociation of gas hydrate, which takes into account the influence of temperature, pressure, pore water chemistry, and the pore size distribution of the sediment is developed.

In the proposed model, the two-phase chemical potential equilibrium relation involving hydrate phase is governed by the following key equation: 


$$
\Delta \mu^{H}+\Delta \mu^{W}=-\frac{2 \sigma V_{l}}{r R T} \cos \theta
$$

where $\mu^{W}$ is the chemical potential of water in the aqueous liquid, $\mu^{H}$ is the chemical potential of water in hydrates (Van der Waals and Platteeum model 1959) and the right-hand term of equation [1] corresponds to the capillary effects on the hydrate phase equilibrium condition (Henry et al. 1999).

In equation [1], $\sigma$ is the surface tension of water-ice interface (Henry et al. 1999), $\theta$ is the porous host-water contact angle, $r$ is the pore radius and $V_{l}$ is the molar volume of water. All the reference properties in differential terms, $\Delta$, are between empty cavity and the aqueous phase. The thermodynamical details concerning equation 1 are presented in appendix A.

\subsection{Prediction and phase equilibrium for gas hydrate}

In this section, the effect of different parameters (gas components, salinity and mean pore size) on the gas hydrate phase stability is studied. A set of physical parameters has been collected from various literature sources and verified for the theoretical calculation of different gas (methane, ethane, propane, ...) hydrate components and for the two different hydrate structures (structure I, sI and structure II sII).

First, the effect of gas components on the stability law of gas hydrate is considered. Three cases were tested (1: pure methane, 2: $98 \%$ of methane and $2 \%$ of ethane, $3: 96.7 \%$ of methane and $3.2 \%$ of ethane). Simulation results of the stability curve of the three cases are shown in Figure 3-a. One can see that the effect of the gas components cannot be neglected in the thermodynamic formulation of the gas hydrate stability law. Indeed, for a temperature of $280^{\circ} \mathrm{K}$, curves form Figure 3 -a show a difference of around $18 \%$ of the gas-hydrate equilibrium pressure (or water depth) between the first and the third case.

In the second calculation, the effect of the pore size on the phase stability of methane hydrate was tested. Three cases were considered (1: bulk hydrate, 2: pore radius of $10^{-8} \mathrm{~m}$ and 3: pore 
radius of $710^{-9} \mathrm{~m}$ ). Simulation results are presented in Figure 3-b. For a constant temperature of $280 \mathrm{~K}$, a difference of around $60 \%$ of the gas-hydrate equilibrium pressure can be observed from Figure 3-b between the first and the third case. Handa and Stupin (1992) determined equilibrium conditions for methane hydrate in porous silica gel. The mean pore size distribution in this material was around $710^{-9} \mathrm{~m}$. Figure 3-b presents the experimental results from Handa and Stupin (1992). A good agreement is obtained between experimental data and theoretical results.

In the third case, the effect of the salinity on the stability curve of methane hydrate is considered. Three cases were tested using the developed model (1: $0 \%$ weight of $\mathrm{NaCl}, 2: 3 \%$ wt $\mathrm{NaCl}$ and 3: 3.5\% wt NaCl). Once again, simulation results presented in Figure 3-c show the high sensitivity of the gas hydrate stability curve to the change of salinity. For a constant temperature of $280 \mathrm{~K}$, a difference of around $15 \%$ of the gas-hydrate equilibrium pressure was observed between the first and the third case. Experimental results obtained by Dickens and Quinby-Hunt (1994) for methane hydrate stability conditions in seawater (Salinity in 3.35\% wt) are presented in Figure 3-c. For all the pressure range and at any given pressure value, the dissociation temperature of methane hydrate is decreased by approximately $1.1^{\circ} \mathrm{C}$ relative to the pure water system. Figure 3-c shows that the thermodynamic predictions obtained with the model developed in this paper are consistent with the experimental results of Dickens and Quinby-Hunt (1994).

\section{CONSERVATION OF ENERGY}

The analysis of heat transfer with a moving solid-fluid boundary is often referred to as a Stefan problem. For material undergoing a phase transformation, the conservation of energy is given by the following equation:

$$
\bar{C}_{p} \frac{\partial T}{\partial t}+\nabla\left(h_{l} \underline{u_{l}}\right)=\nabla(\bar{\kappa} \nabla T)+\phi L \frac{\partial \eta}{\partial t}
$$


where $h_{l}$ is the enthalpy of the liquid phase and is given by:

$$
h_{l}=C p_{l}\left(T-T_{m}\right)+L
$$

The effective volumetric heat capacity of the medium $\bar{C}_{p}$ is expressed by the following expression:

$$
\bar{C}_{p}=C_{p w} \phi(1-\eta)+C_{p h} \phi \eta+C_{p s}(1-\phi)
$$

For equations [2], [3] and [4] the subscript $s$ denotes the solid phase, the subscript $h$ denotes the hydrate phase and the subscript $l$ denotes the liquid phase; $u_{l}$ is the velocity of the liquid phase, $\phi$ is porosity, $\eta$ is the hydrate fraction, $T$ is temperature, $T_{m}$ is the melting temperature and $L$ is the latent heat of fusion. In equation $2, \bar{\kappa}$ is the effective thermal conductivity of the medium. According to 2001 MBARI Gas Hydrate Workshop conclusions, the thermal conductivity of the hydrate-sediment medium is one of the key knowledge gaps in hydrate modelling. The effective thermal conductivity of any porous solid is bounded by the harmonic and geometric mean of the thermal conductivity of the constituents. In this work, the coefficient $\bar{\kappa}$ is expressed by equation 5 (harmonic mean):

$$
\bar{\kappa}=\frac{\kappa_{l} \kappa_{h} \kappa_{s}}{\kappa_{h} \kappa_{s} \phi(1-\eta)+\kappa_{l} \kappa_{s} \phi \eta+\kappa_{l} \kappa_{h}(1-\phi)}
$$

For free gas trapped in the sediment, the thermal conductivity of the hydrate is replaced by the thermal conductivity of the gas $\left(\kappa_{\mathrm{g}}\right)$ and the hydrate fraction by the gas fraction.

In equation 4, the effect of the gas phase on the volumetric heat capacity is neglected. Indeed,

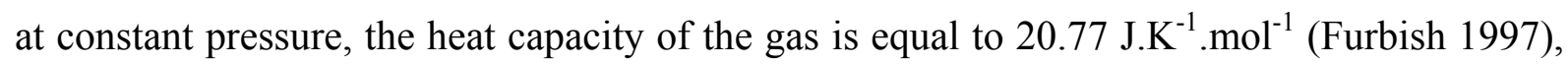
which is around fifty times lower than the heat capacity of the liquid and solid phases.

In this study, the enthalpy form of the conservation energy is considered in one spatial dimension and flow in the liquid is neglected $\left(u_{l}=0\right)$. Under these assumptions, equation [2] is simplified to: 


$$
\bar{C}_{p} \frac{\partial T}{\partial t}=\frac{\partial}{\partial x}\left(\bar{\kappa} \frac{\partial T}{\partial x}\right)+\phi L \frac{\partial \eta}{\partial t}
$$

The complexity to solve equation [6] is the availability of one equation for two unknowns: the temperature $T$ and the hydrate fraction $\eta$.

The conservation of energy of two-phase mixture can be expressed in terms of temperature and total volumetric enthalpy $H$. Indeed:

$$
\frac{\partial H}{\partial t}=\bar{C}_{p} \frac{\partial T}{\partial t}-\phi L \frac{\partial \eta}{\partial t}
$$

Thus, equation [6] is simplified and the enthalpy form of the conservation of energy is given by the following simplified equation:

$$
\frac{\partial H}{\partial t}=\nabla(\kappa \nabla T)
$$

For a pure material, the temperature can be expressed as a function of the enthalpy. For a material with a melting temperature $\mathrm{T}_{\mathrm{m}}, \mathrm{T}(\mathrm{H})$ is defined as :

$$
T(H)=\left\{\begin{array}{lr}
\frac{H}{C p_{s}}+T_{m} & H<0 \\
T_{m} & 0 \leq H \leq L \\
\frac{H-L}{C p_{l}}+T_{m} & H>L
\end{array}\right.
$$

In a porous medium containing gas hydrate, equation [9] becomes:

$$
T(H)=\left\{\begin{array}{lr}
\frac{H}{C p}+T_{m}(p) & H<0 \\
T_{m}(p) & 0 \leq H \leq L \\
\frac{H-L}{C p}+T_{m}(p) & H>L
\end{array}\right.
$$

where $p$ is the hydrostatic pressure. In the case where we can express temperature as a function of enthalpy $T=T(H)$, equation [8] becomes:

$$
\frac{\partial H}{\partial t}=\frac{\partial}{\partial x}(\bar{\kappa} \nabla T(H))
$$


The use of the enthalpy form for the energy conservation equation (equation 11) instead of the temperature form (equation 6) makes the problem easier to solve.

The mathematical details concerning the incremental solution of equation 11 are presented in Sultan et al. (2004). The temperature or pressure of hydrate phase equilibrium is calculated at each time step using equation [1]. At each time step, the fluid flow (Darcy's law) within the sediment is simulated at each node from initial and boundary conditions using the finite difference method. The gas migration is taken into account by diffusion in fluid phase when dissolved using the Fick's law.

\section{EVALUATION OF THE EXCESS PORE PRESSURE GENERATED BY HYDRATE MELTING.}

In this work, the volume conservation is used in order to evaluate the excess pore pressure generated by the melting of the gas hydrate in a soil volume $V$. Volume conservation implies that the over all volume change will be the sum of the volume changes on each components and each phase system (eq. 11) :

$$
\Delta V_{T}=\Delta V_{s}+\Delta V_{w}+\Delta V_{g}+\Delta V_{H}
$$

In equation $11, \Delta V_{s}$ is the volume change of the solid fraction, $\Delta V_{w}$ that of the liquid phase, $\Delta V_{g}$ that of the gas phase, $\Delta V_{H}$ that of the hydrate fraction and $\Delta V_{T}$ is the total volume change of the soil volume $V$. Equation 11 depends on the solubility of the dissolved gas k, the ratio of gas $\mathrm{k}$ to water in the hydrate phase, the fugacity of gas $\mathrm{k}$, the compressibility of the different constituents of the soil but also on the pore pressure. Therefore, equation 11 is solved by iteration in order to evaluate the pore pressure change generated by the formation or dissociation of the gas hydrate. Mathematical details concerning equation 11 are presented in appendix B. An important parameter to evaluate the excess pore pressure is the gas solubility in water, which is presented in Figure 5-a for methane as a function of the hydrostatic pressure for three different temperatures (for mathematical details concerning solubility, see 
appendix B). From Figure 5-a, and as it was mentioned by Handa (1989) the methane solubility increase with the hydrostatic pressure until the inflection point which corresponds to the equilibrium hydrate pressure. The solubility below the point of inflection is for the twophase liquid-gas system, the point of inflection is for the three-phase hydrate-liquid-gas system and above the point of inflection is for the two phase hydrate-liquid system. At the inflection point the concentration of the methane in the liquid phase becomes constant and hydrate formation process continue until all the free gas disappear. At pressure higher than the hydrate equilibrium pressures the gas solubility decrease slightly with the increase of the hydrostatic pressure (Figure 5-a). Figure 5-b presents the ratio of methane to water in the hydrate phase against temperature. Figure 5-a and Figure 5-b show that the ratio of methane to water in the hydrate phase are around 150 times greater than the ratio of methane to water in the aqueous solution. Therefore, the melting of the hydrate phase will generate a huge quantity of methane, which is much higher than the solubility of the dissolved gas in the aqueous solution. Therefore, at short term it is possible to evaluate the excess pore pressure generated by the hydrate melting (see appendix B).

Equations B-1 through B-14 were used to evaluate the pore saturation in gas hydrate against the methane concentration in the aqueous phase at different $\mathrm{T}$ and $\mathrm{P}$ equilibrium conditions (Figure 6). One can observe that the hydrate fraction is not constant for a given $\mathrm{T}$ and $\mathrm{P}$ conditions and it depends on the gas concentration in the aqueous solution. Around $10 \mathrm{mmol}$ of methane for one mol of water in the aqueous solution are needed in order to obtain $5 \%$ of the pore saturation in gas hydrate.

The prediction of the excess pore pressure generated by the melting of gas hydrate (from solid to gas phase) against the temperature is presented in Figure 7 at different initial pore saturation in methane hydrate. The excess pore pressure increases with temperature. The magnitude of the excess pore pressure depends on the initial methane concentration and on 
the hydrostatic pressure. For a hydrostatic pressure of $4 \mathrm{MPa}$, the melting of the methane hydrate will generate around $0.1 \mathrm{MPa}$ for an initial hydrate fraction of around $2.6 \%$ and around $0.3 \mathrm{MPa}$ for an initial hydrate fraction of $52 \%$.

On the other hand, an increase of gas solubility generated by temperature and/or pressure change (Figure 5) leads to a dissociation of hydrate in the hydrate stability zone. This important feature, which is supported by experimental results (see for instance Zhang 2003) and by theory, is unfortunately completely ignored in marine geological and geophysical literatures. Figure 8 presents the pressure vs temperature variations of an experiment in which hydrates were formed and decomposed in a single-phase solution of dissolved $\mathrm{CO}_{2}$ in water (from Zhang 2003). Figure 8-a shows a clear dependence of the pressure on the $\mathrm{CO}_{2}$ solubility in the hydrate stability zone. The formation of the hydrate from the single-phase solution of dissolved $\mathrm{CO}_{2}$ generates an important decrease of the pressure. On the other hand, a dissociation of the $\mathrm{CO} 2$ hydrate in the hydrate stability zone occurs and generates an increase of the pore pressure, which can be clearly identified from (Figure 8-c). These experimental results show once again that neglecting the effect of gas and considering only the temperature and pressure to study the stability of the gas hydrate is too simplistic and ignored the essential of the dynamic of gas hydrate. As it is shown schematically in Figure 9, the consequence of the hydrate dissociation in the hydrate stability zone can be very hazardous. Figure 9 sketches a retrogressive failure surface generated by the hydrate decomposition due to gas solubility in the hydrate stability zone. The considered slope is within the hydrate stability zone (Figure 9a). However the low concentration of the methane over the first meters prevent the formation of the methane hydrate. A temperature and pressure increase will move done the Top of the Gas Hydrate Stability zone (TGHS). The studied slope remains in the gas hydrate stability zone (Figure 9-b). On the other hand, the temperature and pressure increase leads to an increase of the methane solubility and consequently the hydrate decomposed in a single-phase 
solution. The hydrate decomposition generates an excess pore pressure and a weak soil for sufficient hydrate concentrations. The first slope failure (1 in Figure 9-b) occurs in the lower part of the slope. Following the first slope failure, the gas exchange with the water column (2 in Figure 9-b) will remould the upper part of the sediment leading to a second slope failure (3 in Figure 9-b). The mechanism of gas exchange with the water column (4 and 6 in Figure 9c), remoulding of the upper sediment layer and inducing slope failures ( 3 and 5 in Figure 9-c) will retrograde over the slope.

\section{STOREGGA SLIDE}

\subsection{Geological setting}

The Storegga Slide covers an area of $85-90,000 \mathrm{~km}^{2}$, which is one of the world's biggest underwater slides (Figure 10) with its overall volume of $3300 \mathrm{~km}^{3}$ and an estimated area of slide scar of $30000 \mathrm{~km}^{2}$ (Haflidason et al. 2002). This complex slide has earlier been interpreted to be the product of three slide events (Bugge 1983). During the last couple of years, extensive stratigraphical and chronological studies aimed at understanding the continental margin stability and the sedimentary processes within the Storegga Slide area were carried out by the University of Bergen. A number cores (gravity and Selcore) have been collected both inside and outside the slide area for this purpose. The objective of the dating project was to verify the age of the main morphological slide structures of the Storegga Slide area. Haflidason et al. $(2001,2002)$ show that the Storegga Slide has been activated/ mobilised within the same age interval 7.300 radiocarbon age $\left({ }^{14} \mathrm{C}\right) \mathrm{BP}$ or ca. 8150 cal. yrs BP.

The mechanisms that initiate the Storegga Stide in this area are not well understood. While some authors associate the failure of the Storegga Slide with excess pore pressures caused by gas-hydrate dissociation after a thermal warming since last deglaciation, other authors consider that the Storegga Slide may have been triggered by offshore earthquakes. Indeed, the 
Storegga area has occasionally been susceptible to high-magnitude seismicity. However, the examination of the geotechnical data from the northern flank of the Storegga Slide show a soil with a high clay content and low sensitivity which reduce significantly the liquefaction risk due to earthquake (Sultan et al. this volume). On the other hand, the hypothesis of the gas hydrate at the origin of the Storegga Slide is defensible. This is supported by a well-defined bottom-simulating reflection (BSR) identified on seismic profiles from the northern flank of the Storegga Slide (Bugge 1983; Mienert and Bryn, 1997, Mienert et al. 1998, Posewang and Mienert 1999, Bouriak et al. 2000 among others) but without any evidence of the existence of gas hydrate.

Another causal mechanism at the origin of the Storegga Slide was mentioned by Bryn et al. (2002). They considered that "the precondition of the slides is closely related to the preglacial morphology and the glacial history, which causes variation in sedimentation rate and type". Indeed, the glacial - interglacial variability, which induces a sedimentary succession consisting of fine grained marine clays, rapidly overlain by dense glacial clays generates unfavourable shear stress and excess pore pressures in the underlying marine clays. They conclude that deposition in response to glacial - interglacial variability is the main causal factor for instability. Kvalstad et al. (2002) gave a tentative explanation of the triggering mechanism of the initial phase of the Storegga Slide, which is well identified as retrogressive failures. According to Kvalstad et al. (2002) a major earthquake, toe erosion in the deep part of the slope, diapiric and water expulsion processes in the ooze layers could all have contributed to initiate the Storegga Slide. From the above discussion, one can see that the trigger mechanisms that initiate the Storegga Slide in this area are not well identified. Therefore, in this work one of the possible trigger mechanisms at the origin of the Storegga Slide, which is the gas hydrate, is tested over a cross-section from the northern flank of the Storegga Slide. 


\subsection{Thermal, geochemical and geotechnical data}

Thermal and geotechnical data are available from one IMAGES core (MD992288) on the Northern flank of the Storegga Slide (Figure 10). Other geotechnical and geochemical data were used from ODP leg 104, site 644 (Figure 10).

Temperature change histories from 1945 to 1995 at different water depth from the Vøring Plateau, obtained from the Oceanographic Institute, University of Bergen are presented in Figure 11. Variability seems to be largest for water depths less than $900 \mathrm{~m}$ whereas at a depth of more than $1000 \mathrm{~m}$ long-term variation seems to be extremely low. At water depth of $400 \mathrm{~m}$, the maximum temperature change is around $1.5^{\circ} \mathrm{C}$. The thermal gradient from site 6404/5 (Figure 10) shows a linear increase of the temperature with depth with a thermal gradient of around $51^{\circ} \mathrm{C} / \mathrm{km}$.

The design geotechnical data used in the calculation are presented in Table 1 ( $\mathrm{Su}$ : is the undrained shear strength, St: is the sensitivity, c': is the cohesion, $\varphi:$ is the internal friction angle, $\phi:$ is the porosity $, \gamma^{\prime}:$ is the effective unit weight). These design geotechnical data were determined from the available geotechnical data (from ODP sites and MD992288 core for position see Figure 10). The design undrained shear strength profile used in the calculation is presented in Figure 12.

Data of methane concentration vs depth at site 644 were taken from Kvenvolden et al. (1989), and are presented in Figure 13-a. Figure 13-a shows that at depths greater than $55 \mathrm{~m}$, the methane concentrations from site 644 are equivalent to the methane solubility curve at atmospheric pressure and ambient temperature. These results were expected since the measurement of the methane concentration was carried out under atmospheric pressure and laboratory temperature. Besides and according to Kvenvolden et al. (1989), at the site 644, gas pockets, indicating gas expansion, did form in the interval between 80 to $150 \mathrm{mbsf}$ and were possibly the result of gas hydrate decomposition. That is why, in this work, a correction 
of the methane concentration was made, by considering that the local void volumes form in the cores (Figure 13-b) correspond to methane pockets. The corrected curve concerning the methane concentration is presented in Figure 13-a. The correction of the methane profile done in this work is supported by the salinity profile presented in Figure 13-c. Indeed, at the depth where the methane concentration is equal to the methane solubility, a sudden decrease of the salinity was observed. This salinity decreases is probably related to the dissociation of hydrates.

\section{FORMATION AND DISSOCIATION OF GAS HYDRATES OVER THE RECONSTRUCTED STOREGGA SLOPE SINCE LAST DEGLACIATION.}

Based on different geophysical data, Bouriak et al. (2000) proposed a reconstruction of the seafloor topography over the line PSAT69 (Figure 14). The reconstructed seafloor topography is used in this paper in order to study the dynamic of the gas hydrate formation and dissociation since the last deglaciation. The sediment layers are considered parallel to the reconstructed seafloor topography over the line PSAT69. The depths of the different layers are presented in Table 1.

Figure 3 shows the main effect of the gas concentration on the stability law of gas hydrate. In this work, the methane profile presented in Figure 12 is considered as the methane profile within the sediment all over the cross-section PSAT-69 and since the last deglaciation period. So it is clear that the subsequent results concerning the study of the gas hydrate stability within the Storegga slope are strongly dependant on the accuracy of the considered gas profile (Figure 13-a).

The dynamic of the hydrate stability over the Storegga slope was studied under two of the most important changes during and since the last deglaciation: 1) hydrostatic pressure due to the change of the sea level and 2) the increase of the sea water temperature.

The estimation of the sea level change since the last deglaciation was taken from Bard et al. (1990). From a paleotemperature estimation on cores extracted from the Vøring Plateau 
$\left(67^{\circ} 05.01^{\prime} \mathrm{N}-02^{\circ} 54.4^{\prime} \mathrm{E}\right)$. Koç et al. (1993) conclude that during the last deglaciation and the Younger Dryas, relatively extensive sea ice cover was present over the Vøring plateau. Thus, in our calculation we have considered that during this period the temperature was constant and equal to $-1.9^{\circ} \mathrm{C}$ (Figure $\left.11-\mathrm{a}\right)$. Until $9 \mathrm{ky}$, the temperature profile ( $\mathrm{Tb}$ from Figure 11-a) was taken as the mean curve of the temperature of $-1.9^{\circ} \mathrm{C}$ and the present temperature profile (Figure $11-\mathrm{a} \& \mathrm{~b}$ ). Since $9 \mathrm{ky}$ the temperature was taken equal to the mean curve profile presented in Figure 11-b.

\subsubsection{Simulation results}

Figure 15 and Figure 16 present respectively the hydrate fraction and the excess pore pressure over the reconstructed slope for 4 different time steps (-11.85 ky, -11 ky, $-10 \mathrm{ky}$ and $-9 \mathrm{ky})$.

The low concentration of methane in the upper 60 meters of sediment (Figure 12), which is probably related to the methane exchange between bulk water and seawater column, prevent the formation of gas-hydrates in the upper sediment layers (Figure 15-a). The maximum hydrate fraction over the reconstructed slope is around $1 \%$ of the pore volume (Figure $15-\mathrm{a})$. For the first two time steps, the increase of the sea level induces an increase of the hydrostatic pressure of around $400 \mathrm{kPa}$. At higher hydrostatic pressure and higher temperature, the solubility of the methane will increase (Figure 2 and Figure 5-a). Thus, the new hydrostatic pressure condition will induce a dissociation of the gas hydrate at the top of the gas hydrate layer in order to establish the chemical potential equilibrium between the hydrate phase and the liquid phase. The melting of the gas hydrate during this period will induce a decrease of the hydrate fraction (Figure 15-b) and generate an excess pore pressure (Figure 16-b). It is important to mention that the excess pore pressure is generated at the top of the hydrate layer. The maximum value of the excess pore pressure in this period is around $25 \mathrm{kPa}(12 \mathrm{ky}-11 \mathrm{ky})$. At the time step of -10 ky (Figure 15-c and Figure 16-c), the change of the sea level will induce an addition increase of the hydrostatic pressure of around $100 \mathrm{kPa}$. At this period (-10 
ky ago) to the sea level change is added an increase of the seawater temperature. The increase of the seawater temperature and the hydrostatic pressure induce the melting of the gas hydrate over a layer of around $15 \mathrm{~m}$ (Figure 15-c). The result is a generation of excess pore pressure of around $35 \mathrm{kPa}$ and a decrease of the soil resistance due to the disappearing of hydrates, which bond the sediments in which it occurs. The stability of the reconstructed slope was evaluated at each time steps. The details of the stability study of the reconstructed slope are presented in the next section. However, it is important to mention that the seafloor topography in Figure 15- c-d and Figure 16-c-d was update at each time step by taking out the geometry of the sliding surfaces obtained under drained conditions.

At the time step of -9 ky (Figure 15-d and Figure 16-d), the new slope topography and the increase of the temperature induce the melting of a new layer of hydrate, which generates an increase of the excess pore pressure and a decrease of the soil resistance. The hydrate fraction at $-9 \mathrm{ky}$ is presented in Figure 15-d. One can see a sudden decrease of the hydrate fraction over the reconstructed slope (Figure 15-d). The hydrate fraction is less than $0.6 \%$ of the pore volume. The maximum excess pore pressure generated over the reconstructed slope is around $38 \mathrm{kPa}$ (Figure 16-d).

\section{EVALUATION OF THE INSTABILITY OF THE RECONSTRUCTED STOREGGA SLOPE SINCE LAST DEGLACIATION.}

Different methods (limit equilibrium method, limit analysis method, energetic method and finite element method) were proposed in the literature to solve the problem of slope stability analysis. However, the limit equilibrium methods are commonly used because of the simplicity with which complex geometry, soil heterogeneity and pore water pressure conditions can be taken into account. In this paper we used the generalised limit analysis method that allowed: 1) to take into account the heterogeneity of the marine sediment by affecting the relevant geotechnical properties to the sediment according to its nature; 2) to calculate the pore pressure in each node from initial and boundary conditions for transient 
state or steady-state regime; 3 ) to determine all the possible concave slip surfaces (circle or non-circle); 4) to calculate the safety factor on all the selected slip surfaces and 5) to search for the critical slip surface where the safety factor is minimal.

This method requires the user to postulate a collapse mechanism by which failure can occur. By examining a number of different mechanisms, the critical one where the safety factor is minimal is found. Thus, all the possible concave failure surfaces in a vertical cross-section are automatically generated. In this study we have adopted the General Formulation (GLE Fredlund and Krahn 1977), which fully satisfies the equilibrium. Failure is assumed to occur by sliding of the soil along a non-circular slip surface. By examining overall moment equilibrium about an assumed centre of rotation and overall force equilibrium, two different expressions are obtained for the factor of safety, respectively $F O S_{m}$ (for moment equilibrium) and $\mathrm{FOS}_{f}$ (for force equilibrium) where:

$$
F O S=\frac{\text { Shear strength of soil (resisting force or moment) }}{\text { Shear stress required for equilibrium (driving force or moment) }}
$$

The safety factor is determined by two series of iterative numerical procedure. The first iterative procedure is used to calculate $F O S_{m}$ and $F O S_{f}$, while the second iterative procedure is used to find the internal inter-slices forces in order to obtain $F O S_{m}$ equal to $F O S_{f}$ for the same failure surface. In a vertical cross-section, each node often belongs to several slip surfaces for each of which a safety factor is computed. The minimal of these safety factors $(F O S)$ is affected to each node and the contour map of FOS can be plotted over the whole vertical cross-section. Details of the used method are presented in Sultan et al. (2001).

At each time step where the factor of safety was evaluated under drained and undrained conditions, data obtained from the gas hydrate model concerning the sediment areas with hydrates melting and excess pore pressure were introduced in the slope stability model.

For the cross-section PSAT69, The evaluation of the factor of safety was carried out under drained and undrained conditions. As it was mentioned before, the degradation of the soil 
resistance due to hydrate melting was unfortunately not considered accurately in this study; for the soil layers where the hydrate melts, the drained and undrained shear strength were replaced by the remoulded shear strength.

Figure 17-a, b, c, d show the factor of safety calculated under drained conditions for four different time steps (-11.85 ky, $-11 \mathrm{ky},-10 \mathrm{ky}$ and $-9 \mathrm{ky})$. At $-11.85 \mathrm{ky}$, the slope is safe and the minimum factor of safety over the slope is around 13 (Figure 17-a). At -11 ky, the melting of the gas hydrate (Figure 15-b) induce a decrease of the soil resistance and an increase of the excess pore pressure (Figure 16-b). Consequently the FOS decreases in the lower part of the reconstructed slope (Figure 17-b). The minimum value of the FOS is around 1.2. The critical surface is initiated at the top of the gas hydrate layer. At -10 ky, a section of the reconstructed slope was slipped due to the decrease of the soil resistance and the increase of the excess pore pressure. The new seafloor topography was update by taking out the area where the drained factor of safety is less than 1 . The factors of safety $40 \mathrm{~m}$ below the seabed all over the lower part of the reconstructed slope are lower than 1, which will induce a retrogressive slope failure (Figure 17-c). At $9 \mathrm{ky}$, a new critical failure surface $(\mathrm{FOS}<1)$ is observed at the steepest part of the slope. As it was shown previously, the failure surfaces are initiated at the top of the hydrate layer and not at the bottom of the hydrate as it is often suggested.

\section{CONCLUSIONS}

In this paper, we have developed a theoretical study of the thermodynamic chemical equilibrium of gas hydrate in sediment, which is based on models previously reported by Handa (1989), Sloan (1998) and Henry et al. (1999). In this study we took into account the influence of temperature, pressure, pore water chemistry, and the sediment pore size distribution. A numerical model of the formation or dissociation of gas hydrate, which occurs in response to temperature, pressure and gas concentrations changes, was developed. This model fully accounts for the latent heat effects, as done by Chaouch and Briaud (1997) and 
Delisle et al. (1998). The model uses a new formulation based on the enthalpy form of the law of conservation of energy. The model allows the evaluation of the excess pore pressure generated during gas hydrate dissociation.

A parametric study showed that neglecting the gas effect on the gas hydrate stability laws induce:

- An overestimation of the thickness of the hydrate zone;

- A significant error concerning the stability curve of the hydrate equilibrium;

- A wrong hypothesis by considering a constant hydrate fraction of the pore volume within the sediment, while it can be calculated from the gas concentration; Simulation results show that the hydrate fraction depends strongly on the hydrostatic pressure (Figure 6);

- The impossibility to estimate the excess pore pressure generated by the melting of the gas hydrate inside and outside the hydrate stability zone

The developed model show that due to a temperature increase, hydrates dissociate first at the top of the hydrate occurrence zone in order to ensure the chemical equilibrium with the surrounding bulk water and not as it is often suggested at the bottom of the hydrate zone.

In the second part of the paper, we present and discuss an application of the numerical model developed in the present work through a back-analysis of the case of the giant Storegga Slide on the Norwegian margin. Two of the most important changes during and since the last deglaciation (hydrostatic pressure due to the change of the sea level and the increase of the sea water temperature) were considered in the calculation. Under the assumption of a unique shear strength profile (Figure 12) and unique gas profile (Figure 13) all over the slope, simulation results show that melting of gas hydrate can be at the origin of a retrogressive failure over the Storegga slope. Moreover, and due to the gas solubility, the failure interface is initiated at the top of the hydrate layer and not at the bottom of the hydrate stability zone. 
Acknowledgements. This work has been developed within the European project COSTA (EVK3-1999-00028). An insightful review of Tore Kvalstad and an anonymous reviewer helped to improve an earlier version of the manuscript. 


\section{Appendix A}

The governing equation that predicts the chemical potential of water in hydrates is based on Van der Waals and Platteeum model (1959) and is given by the following equation:

$$
\frac{\Delta \mu^{H}}{R T}=\sum_{j=1}^{2} v_{j} \ln \left(1-\sum_{k} y_{k_{i}}\right)
$$

where $\mathrm{j}$ denotes cavities which guest molecules can occupy, $v_{j}$ is the number of type $j$ cavities per water molecule in the lattice and $y_{k_{i}}$ is the fractional occupation of cavity type $i$. This

fractional occupancy can be expressed in a Langmuir type manner as:

$$
y_{k_{i}}=\frac{C_{k_{i}} f_{k}}{1+\sum_{j} C_{j_{i}} f_{j}}
$$

where $C_{k_{i}}$ is the Langmuir constants of the cavity $i$ for gas $k$ and $f_{k}$ is the fugacity of gas $k$.

The Langmuir constants are temperature dependent functions that describe the potential interaction between the encaged guess molecule and the water molecules surrounding it. They are evaluated by assuming a spherically symmetrical potential, which is described as

$$
C_{k i}=\frac{4 \pi}{k T} \int_{0}^{R-a} \exp \left(-\frac{\varpi(r)}{k T}\right) r^{2} d r
$$

where $\varpi(r)$ is the cell potential function of guest $\mathrm{k}$ in cell $\mathrm{i}$. The detailed expression of $\varpi(r)$ is given by Sloan (1998). The Soave-Redlick-Kwong equation of state (1972) method was used to calculate the fugacity. The chemical potential of water in the aqueous liquid is presented in the following equation:

$$
\frac{\Delta \mu^{W}}{R T}=\frac{\Delta \mu^{0}}{R T}+\int_{P 0}^{P} \frac{\Delta v_{w}}{R T} d p-\int_{T 0}^{T} \frac{\Delta h_{w}}{R T^{2}} d T-\ln \left(\gamma_{w} X_{w}\right)
$$

where, 
$\frac{\Delta \mu^{0}}{R T}$ is the difference in chemical potential between empty hydrate cage and ice or aqueous phase in equilibrium with hydrate and at reference conditions (Sloan, 1998);

$\Delta v_{w}$ is the difference in molar volume between empty hydrate and the aqueous phase;

$\Delta h_{w}$ is the difference in enthalpies between empty hydrate and the aqueous phase;

$\gamma_{w}$ is the activity coefficient of liquid water;

$T:$ Temperature of hydrate formation;

$P$ : Pressure in the liquid phase;

$R$ : Gas constant, $R=8.3144126 \mathrm{~J} / \mathrm{mol}-\mathrm{K}$;

The equilibrium pressure and temperature conditions were calculated by solving the following equation, which is a combination of equations 1 through 5:

$$
\frac{\Delta \mu^{0}}{R T}+\int_{P 0}^{P} \frac{\Delta v_{w}}{R T} d p-\int_{T 0}^{T} \frac{\Delta h_{w}}{R T^{2}} d T-\ln \left(\gamma_{w} X_{w}\right)+\sum_{j=1}^{2} v_{j} \ln \left(1-\sum_{k} y_{k_{i}}\right)=-\frac{2 \sigma V_{l}}{r R T} \cos \theta
$$

where, $T_{0}(=273.15 \mathrm{~K})$ and $P_{0}(0.101328 \mathrm{MPa})$ are the reference temperature and pressure. 


\section{Appendix B}

The total volume change of the soil is given by the following equation:

$$
\Delta V_{T}=m_{v} V \Delta \sigma^{\prime}
$$

where $m_{v}$ is the compressibility of the soil skeleton under the effective mean stress $\Delta \sigma^{\prime}$.

The volume change of the solid phase is given by the following equation:

$$
\Delta V_{s}=\left(m_{s} \Delta \sigma^{\prime}+m_{s i} \Delta u_{w}\right) V_{s}
$$

where $m_{s}$ is the mineral compressibility modulus under the effective mean stress $\Delta \sigma^{\prime}$ and $m_{s i}$ is the mineral compressibility modulus under an isotropic pore pressure $\Delta u_{w}$.

The water volume change $\Delta V_{w}$ (eq. B-3) can be divided into two parts; the first part corresponds to the water compressibility under the isotropic pore pressure $\Delta V_{w c}$ (eq. B-4) and the second part $\Delta V_{w H}$ corresponds to the water volume change generated by the formation or dissociation of the gas hydrate. In equation B-4, $m_{w}$ is the water compressibility modulus.

$$
\begin{aligned}
& \Delta V_{w}=\Delta V_{w c}+\Delta V_{w H} \\
& \Delta V_{w c}=m_{w} V_{w} \Delta u_{w}
\end{aligned}
$$

$\Delta V_{w H}$ is given by the following equation:

$$
\Delta V_{w H}=\bar{V}_{1} \frac{\Delta V_{H H}}{V_{e}}
$$

where $V_{e}$ is the volume of the hydrate lattice per mol of water and $\bar{V}_{l}$ is the partial molar volume of water in the solution at $\mathrm{T}$ and $\mathrm{P}$. For hydrate dissociation generated by a decrease of the gas concentration in the stability field of gas hydrate, $\Delta V_{w H}$ is given by the following equation:

$$
\Delta V_{w H}=\left(\overline{V_{l}}+\frac{\bar{V}_{2 k}}{n_{k}}\right) \frac{\Delta V_{H H}}{V_{e}}
$$


where $\bar{V}_{2 k}$ is the partial molar volume of gas $\mathrm{k}$ in the aqueous solution and $1 / \mathrm{n}_{\mathrm{k}}$ is the ratio of gas $\mathrm{k}$ to water in the hydrate phase.

The gas volume change $\Delta V_{g}$ is divided into three parts (eq. 18):

$$
\Delta V_{g}=\Delta V_{g c}+\Delta V_{g H}+\Delta V_{g s}
$$

where $\Delta V_{g c}$ corresponds to the gas compressibility and is evaluated from the Soave's state equation. $\Delta V_{g c}$ is expressed by the equation B- 8 where $m_{g}$ is the equivalent compressibility of the gas and is evaluated from the Soave's equation:

$$
\Delta V_{g c}=m_{g} V_{g} \Delta u_{g}
$$

$\Delta V_{g H}$ corresponds to the volume of gas generated or used by the gas hydrate dissociation or formation. This quantity is evaluated from $1 / \mathrm{n}_{\mathrm{k}}$, which is the ratio of gas $\mathrm{k}$ to water in the hydrate phase. $\Delta V_{g H}$ is given by the following equation :

$$
\Delta V_{g H}=\operatorname{Volume}\left(-\frac{1}{n_{k}} \frac{\Delta V_{H H}}{V_{e}}+\operatorname{mole}\left(\Delta V_{g s}\right)\right)
$$

where $\Delta V_{H H}$ is the volume of the dissociated or formed hydrate and $\Delta V_{g s}$ is the volume related to gas dissolution/exsolution in the water.

The solubility of the gas $x_{2 k}$ in an aqueous solution depends on several parameters and is given by the following equation (Handa 1989):

$$
x_{2 k}=\frac{f_{k}}{H \exp \left(\frac{\bar{V}_{2 k}(P-1)}{R T}\right)}
$$

where $H$ is the Henry's law constant

$f_{k}$ is the fugacity of gas $k$.

The dependence of the solubility of dissolved gas on pressure in equilibrium with hydrate phase is given by Handa (1989) (equation B-11): 


$$
\left(\frac{\partial \ln \left(x_{2 k}\right)}{\partial P}\right)_{T}=\frac{1}{R T} \frac{V_{e}-\overline{V_{l}}-\frac{\overline{V_{2 k}}}{n_{k}}}{\frac{1}{n_{k}}-\frac{x_{2 k}}{1-x_{2 k}}}
$$

where

$$
n_{k}=\frac{1}{\sum v_{i} y_{k i}}
$$

The hydrate volume change $\Delta V_{H}$ is divided into two parts (eq. B-13):

$$
\Delta V_{H}=\Delta V_{H c}+\Delta V_{H H}
$$

where $\Delta V_{H c}$ correponds to the compressibility of the hydrate phase under a hydrostatic pressure and $\Delta V_{H H}$ is the volume of the dissociated or formed hydrate. $\Delta V_{H c}$ is given by the following equation where $m_{H}$ is the hydrate compressibility modulus under an isotropic pore pressure $\Delta u_{w}$.

$$
\Delta V_{H c}=m_{H} V_{H} \Delta u_{w}
$$




\section{REFERENCES}

Bard, E., Hamelin, B., Fairbanks, R. G., Zindler A., 1990. Calibration of the 14C timescale over the past 30,000 years using mass spectrometric U-Th ages from Barbados corals. Nature $345,405-410$.

Bouriak, S., Vanneste, M., Saoutkine, A., 2000. Inferred gas hydrates and clay diapirs near the Storegga Slide on the southern edge of the Vøring Plateau, offshore Norway. Marine Geology 163, Issues 1-4, 125-148.

Bryn, P., Berg, K., Lien, R., Solheim, A., Ottesen, D., Rise, L. 2002. The Storegga geomodel and its use in slide risk evaluation: geological and geotechnical site investigations in the Storegga Slide area. Proc. Offshore Site Investigation and Geotechnics: diversity and sustainability, London, UK, pp. 219-232.

Bugge, T., 1983. Submarine slides on the Norwegian continental margin, with special emphasis on the Storegga area. Continental Shelf and Petroleum Research Institute (IKU) Publication 110, Trondheim, Norway.

Chaouch, A., Briaud, J.-L., 1997. Post melting behavior of gas hydrates in soft ocean sediments, OTC-8298, in 29th offshore technology conference proceedings, v. 1, Geology, earth sciences and environmental factors: Society of Petroleum Engineers, 217-224.

Davie, M. K., Buffett, B. A., 2001. A numerical model for the formation of gas hydrate below the seafloor. J. Geophys. Res. 106, No. B1, 497.

Delisle, G., Beiersdorf, H., Neben, S., Steinmann, D., 1998. The geothermal field of the North Sulawesi accretionary wedge and a model on BSR migration in unstable depositional environments. in Henriet, J.-P.; Mienert, J. (Ed.): Gas hydrates: relevance to world margin stability and climate change. Geological Society Special Publication, 137. The Geological Society: London, UK, pp. 267-274.

Dickens, G.R., Quinby-Hunt, M.S., 1994. Methane hydrate stability in seawater. Geophysical Research Letters 21(19), 2115-2118.

Egeberg, P.K., Dickens, G.R., 1999. Thermodynamic and pore water halogen constraints on gas hydrate distribution at ODP Site 997 (Blake Ridge). Chem. Geol. 153, 53-79.

Fredlund, D. G., Krahn., J., 1977. Comparison of slope stability methods of analysis. Canadian Geotechnical Journal 14, 429-439.

Furbish, D. J., 1997. Fluid physics in Geology. Oxford University press.

Haflidason, H., Sejrup, H. P., Bryn, P., Lien, P., 2001. The Storegga Slide; Chronology and Flow Mechanism, EUG XI Abstracts, pp. 740.

Haflidason, H., Sejrup, H.P., Bryn, P., Lien, R, Masson, D., Jacobs, C., Huehnerbach, V. Berg, K., 2002. The architecture and slide mechanism of the Storegga Slide, Mid Norwegian 
margin. The Norwegian Petroleum Society, Annual Meeting in Trondheim October 2002.NGF Abstracts and Proceedings No. 2, pp. 80-81.

Handa, Y.P., 1989. Effect of Hydrostatic Pressure and Salinity on the Stability of Gas Hydrates. J. Phys. Chem. 94, 2652-2657.

Handa, Y.P., Stupin, D., 1992. Thermodynamic properties and dissociation characteristics of methane and propane hydrates in 70- $\AA$-radius silica-gel pores. J. Phys. Chem. 96, 8599-8603.

Henry, P., Thomas, M.; Clennell, M.B., 1999. Formation of Natural Gas Hydrates in Marine Sediments 2. Thermodynamic Calculations of Stability Conditions in Porous Sediments," J. Geophys. Res. 104, 23005.

Koç, N., Jansen, E., Haflidason, H., 1993. Paleoceanographic reconstructions of surface ocean conditions in the Greenland, Iceland and Norwegian seas through the last $14 \mathrm{ka}$ based on diatoms. Quaternary Science Reviews 12, 115-140.

Kvalstad, T.J., Gauer, P., Kaynia, A.M., Nadim, F., 2002. Slope stability at Ormen Lange. Proc. Offshore Site Investigation and Geotechnics: diversity and sustainability, London, UK, pp. 233-250.

Kvenvolden KA, Golan-Bac M, McDonald TJ, Pftaum RC, and Brooks JM (1989) Hydrocarbon gases in sediment of the Voring plateau, Norwegian Sea. In: Eldholm O, Thiede J, and Taylor E (Ed) Proceedings of the Ocean Drilling Program, Scientificc Results 104 : $319\} 326$

Mienert, J., Bryn P., 1997. Gas hydrate drilling conducted on the European Margin. EOS, Transactions, American Geophysical Union, 78: 49, 567-571.

Mienert, J., Posewang, J. \& Baumann, M., 1998. Gas hydrates along the north-eastern Atlantic margin: possible hydrate bound margin instabilities and possible release of methane. in Henriet, J.-P. \& Mienert, J. (eds); Gas hydrates: Relevance to world margin stability and climatic change, Geological Society of London, Special Publication, 137, pp. 275-291.

Mienert, J., Posewang J., Lukas, D., 2001. Changes in the Hydrate Stability Zone on the Norwegian Margin and their Consequence for Methane and Carbon Releases into the Oceanosphere. In: Schäfer, P., Ritzrau, W., Schlüter, M., and Thiede (Eds.), The Northern North Atlantic: A changing Environment, Springer Verlag, New York, pp. 281-290.

Posewang, J., Mienert, J., 1999. The enigma of double BSRs: Indicators for changes in the hydrate stability field. Geo-Marine Letters 19, 157-163.

Rempel, A.W., Buffett, B.A., 1997. Formation and accumulation of gas hydrate in porous media. Journal of Geophysical Research 102 (B5), 10151-10164.

Rempel, A.W., Buffett, B.A., 1998. Mathematical models of gas hydrate accumulations. in Henriet, J.-P. \& Mienert, J. (eds); Gas hydrates: Relevance to world margin stability and climatic change, Geological Society of London, Special Publication 137, 63-74. 
Sloan, E.D. Jr., 1998. Clathrate hydrates of natural gases. Marcel Dekker Inc., 2nd edition, New York.

Soave G., 1972. Equilibrium constants from a modified Redlich-Kwong equation of state. Chemical Engineering Science 27, 1197-1203.

Sobkowicz, J.C., Morgenstern, N.R. 1984. The undrained equilibrium of gassy sediments. Canadian Geotechnical Journal 21, 439-448.

Sultan N., Cochonat P., Bourillet J.F., Cayocca F., 2001. Evaluation of the risk of marine slope instability: a pseudo- 3D approach for application to large areas. Marine Georesources and geotechnology 19, 107-133.

Sultan, N., Cochonat, P., Canals, M., Cattaneo, A., Dennielou, B., Haflidason, H., Laberg, J. S., Long, D., Mienert, J., Trincardi, F., Urgeles, R., Vorren, T.O., Wilson, C., this volume. Triggering mechanisms of slope instability processes and sediment failures on continental margins: A geotechnical approach. This volume.

Sultan, N., Foucher, J.P., Cochonat, P., Tonnerre, T., Bourillet, J.F., Ondreas, H., Cauquil, E. and Grauls, D., 2004. Dynamics of gas hydrate: case of the Congo continental slope. Marine Geology, 206, 1-18.

Van der Waals, J.A., Platteeuw , J.C., 1959. Adv. Chem. Phys. 2, p. 2-57.

Wheeler, S.J., 1988-a. A Conceptual Model for Soils Containing Large Gas Bubbles, Geotechnique, 38 No.3., 389-397.

Wheeler, S.J., 1988-b. The Undrained Shear Strength of Soils Containing Large Gas Bubbles, Geotechnique 38 No.3, 399-413.

Xu, W., Ruppel, C., 1999. Predicting the occurrence, distribution and evolution of methane gas hydrates in porous marine sediment. Journal of Geophysical Research 104, 5081-5096.

Zhang, Y., 2003. Formation of hydrate from single-phase aqueous solutions. Internal report, University of Pittsburgh, $77 \mathrm{p}$. 


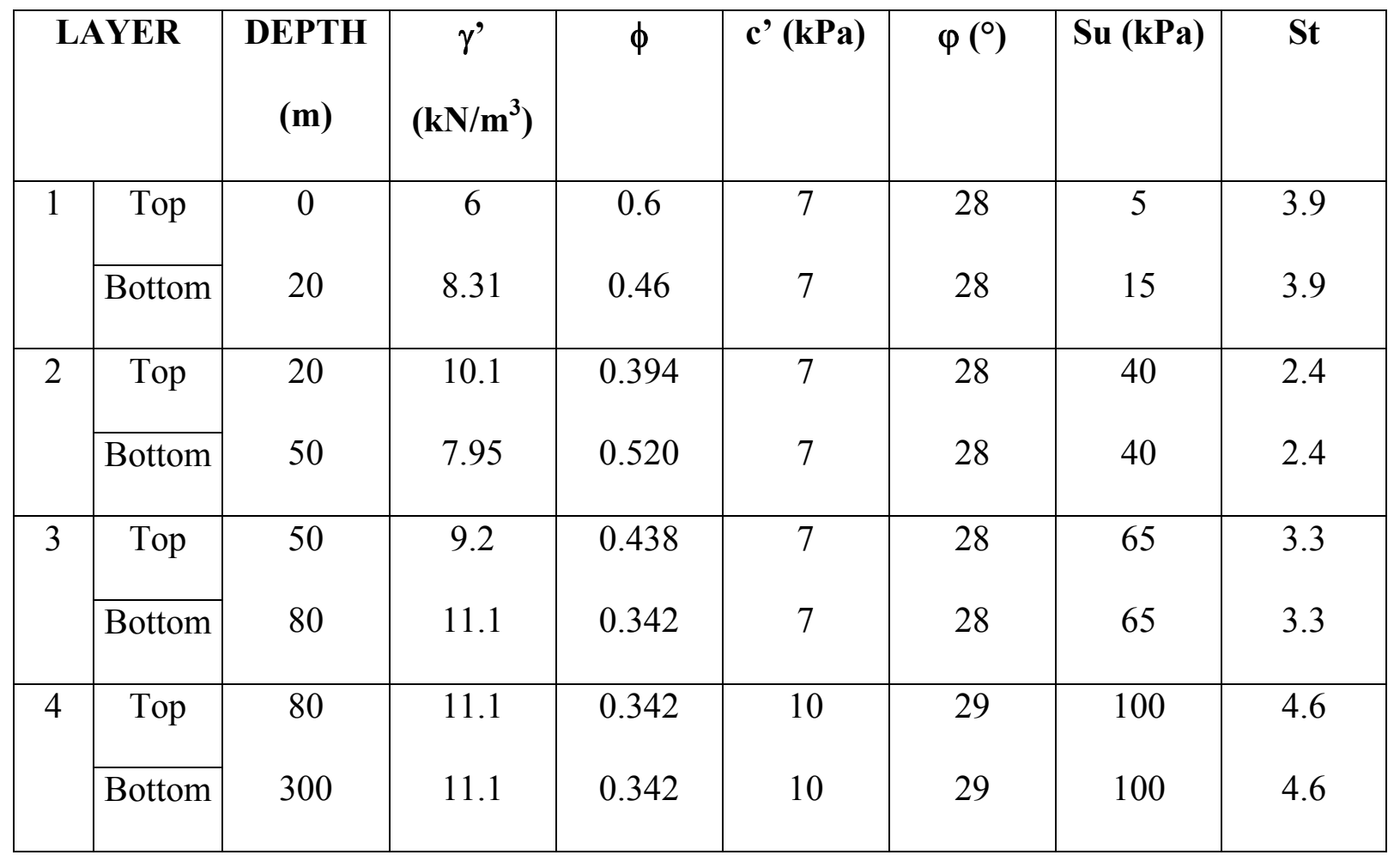

Table 1. Design parameters using in the calculation. 


\section{Figure Captions}

Figure 1. Diagram describing the link between hydrate melting and geohazards.

Figure 2. The relationship among the actual zone of gas hydrate (MHZ), the zone of methane gas hydrate stability (MHSZ), and the free gas zone for a particular geotherm and an assumed seafloor pressure corresponding to $2500 \mathrm{~m}$ water depth (from Xu and Ruppel, 1999).

Figure 3. a) Effect of gas components on the stability law of gas hydrate b) effect of the mean pore radius on the stability law of methane hydrate and c) effect of salinity on the stability law of methane hydrate.

Figure 4. Temperature-enthalpy diagram

Figure 5. a) Solubility of methane in water Vs. temperatures and pressure. The inflection point corresponds to the equilibrium hydrate pressure. The solubility below the point of inflection is for the two-phase liquid-gas system, the point of inflection is for the three phase hydrateliquid-gas system and above the point of inflection is for the two phase hydrate-liquid system b) Ratio of methane to water in the hydrate phase.

Figure 6. Pore saturation in gas hydrate as a function of temperature and pressure.

Figure 7. Excess pore pressure generated by the melting of methane hydrate at different gas hydrate pore saturation. For a hydrostatic pressure of $4 \mathrm{MPa}$, the melting of the methane hydrate will generate around 0.3 MPa for an initial hydrate fraction of $52 \%$. 
Figure 8. a) Pressure vs Temperature history of an experiment in which hydrates were formed and decomposed in a single-phase solution of dissolved $\mathrm{CO}_{2}$ in water. b) $\mathrm{dP} / \mathrm{dT}$ vs. Temperature for dissociation of $\mathrm{CO}_{2}$ hydrate in a single-phase solution. (modified from $\mathrm{Yi}$ Zhang 2000).

Figure 9. Sketch of a retrogressive failure surface generated by the hydrate decomposition due to gas solubility in the hydrate stability zone. a) the low concentration of the methane over the first meters prevent the formation of the methane hydrate. The considered slope is within the hydrate stability zone b) due to a temperature and pressure increase the TGHS will move done. The considered slope remains in the gas hydrate stability zone. The temperature and pressure increase leads to an increase of the methane solubility and consequently the hydrate decomposed in a single-phase solution. The hydrate decomposition generates an excess pore pressure and a weak soil for sufficient hydrate concentrations. The first slope failure occurs in the lower part of the slope c) after the first slope failure, the gas exchange with the water column (2) will remould the upper part of the sediment leading to a second slope failure (3). The mechanism of gas exchange with the water column $(4,6)$, remoulding of the upper sediment layer and inducing slope failures $(3,5)$ will retrograde.

Figure 10. Bathymetry of the Storegga Slide including ODP drill sites, core location (MD992288) and the PSAT69 line position

Figure 11. Temperature history versus water depth 
Figure 12. Undrained shear strength design profile based on data from core MD99-2288 and ODP site 644

Figure 13. a) Methane concentration vs depth at site 644 from Kvenvolden et al. (1989) and corrected methane profile proposed in this work b) Local void volume form in the cores and c) salinity vs depth at site 644 .

Figure 14. Reconstruction of the seafloor topography over the line PSAT69 (from Bouriak et al. 2000)

Figure 15. Hydrate fraction over the reconstructed slope as a function of time. For the $10 \mathrm{ky}$ and $9 \mathrm{ky}$ graphs, the seafloor was update from the calculation of the slope stability under drained conditions.

Figure 16. Distribution of the excess pore pressure over the reconstructed slope as a function of time. For the $10 \mathrm{ky}$ and $9 \mathrm{ky}$ graphs, the seafloor was update from the calculation of the slope stability under drained conditions.

Figure 17. Factor Of Safety (FOS) under drained conditions over the reconstructed slope as a function of time. 


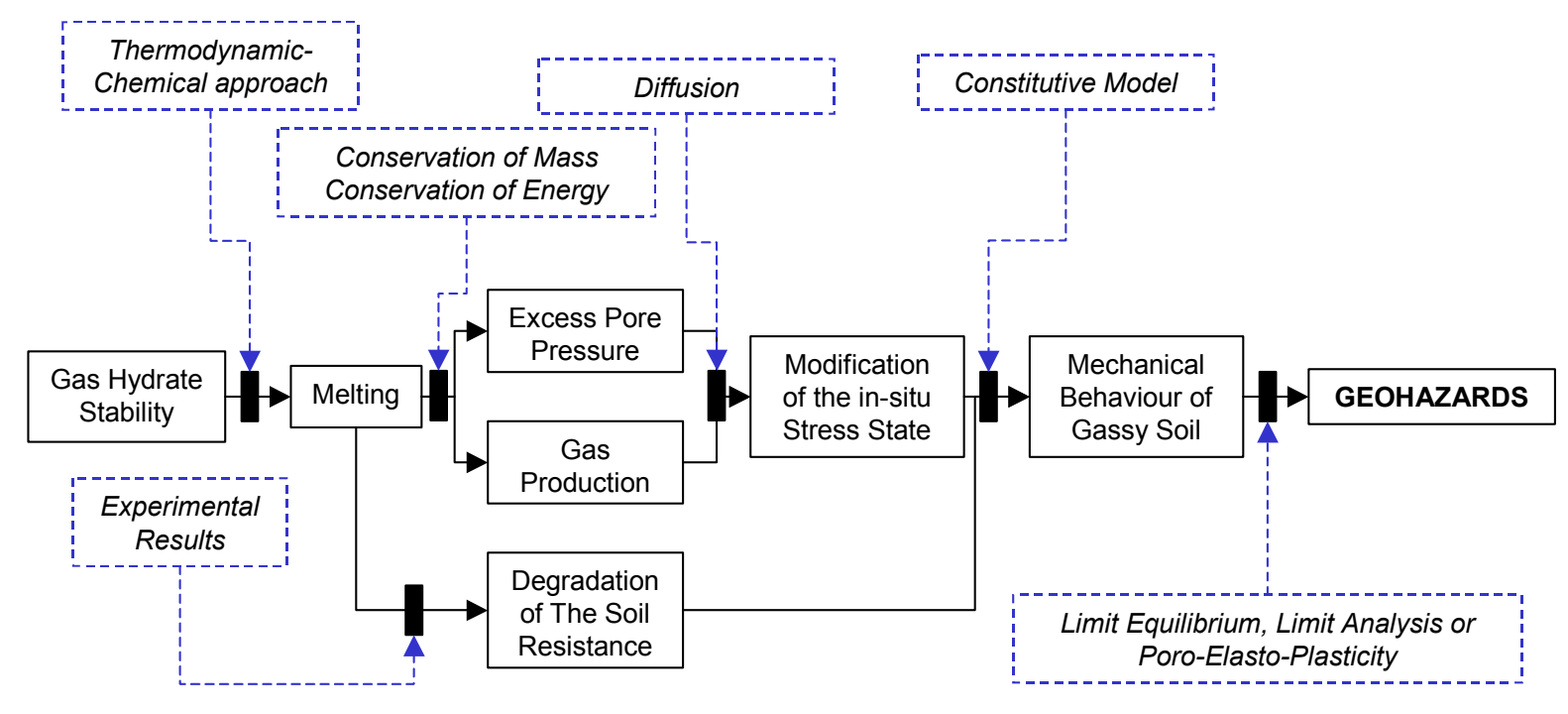

Figure 1. Diagram describing the link between hydrate melting and geohazards. 


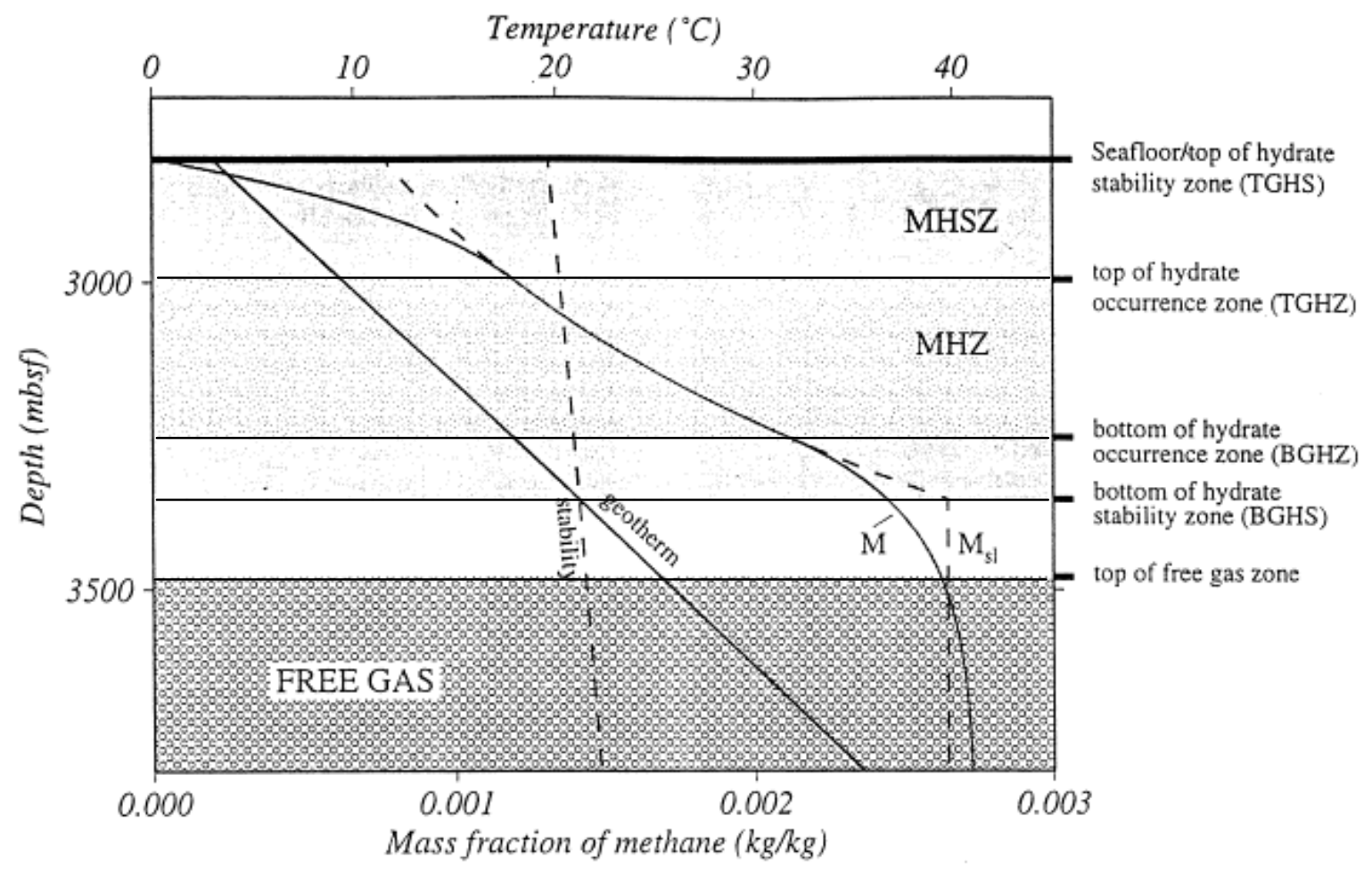

Figure 2. The relationship among the actual zone of gas hydrate (MHZ), the zone of methane gas hydrate stability (MHSZ), and the free gas zone for a particular geotherm and an assumed seafloor pressure corresponding to 2500 m water depth (from Xu and Ruppel, 1999). 

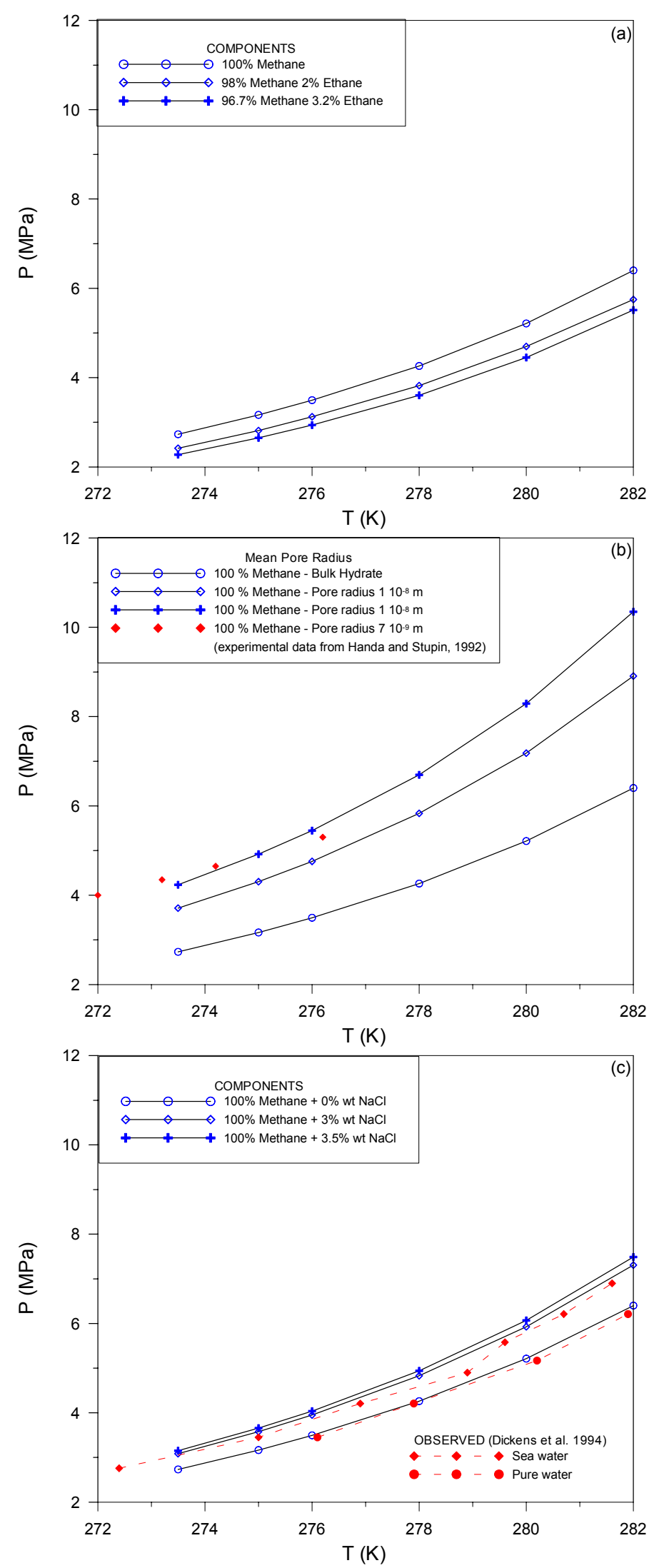

Figure 3. a) Effect of gas components on the stability law of gas hydrate b) effect of the mean pore radius on the stability law of methane hydrate and c) effect of salinity on the stability law of methane hydrate. 


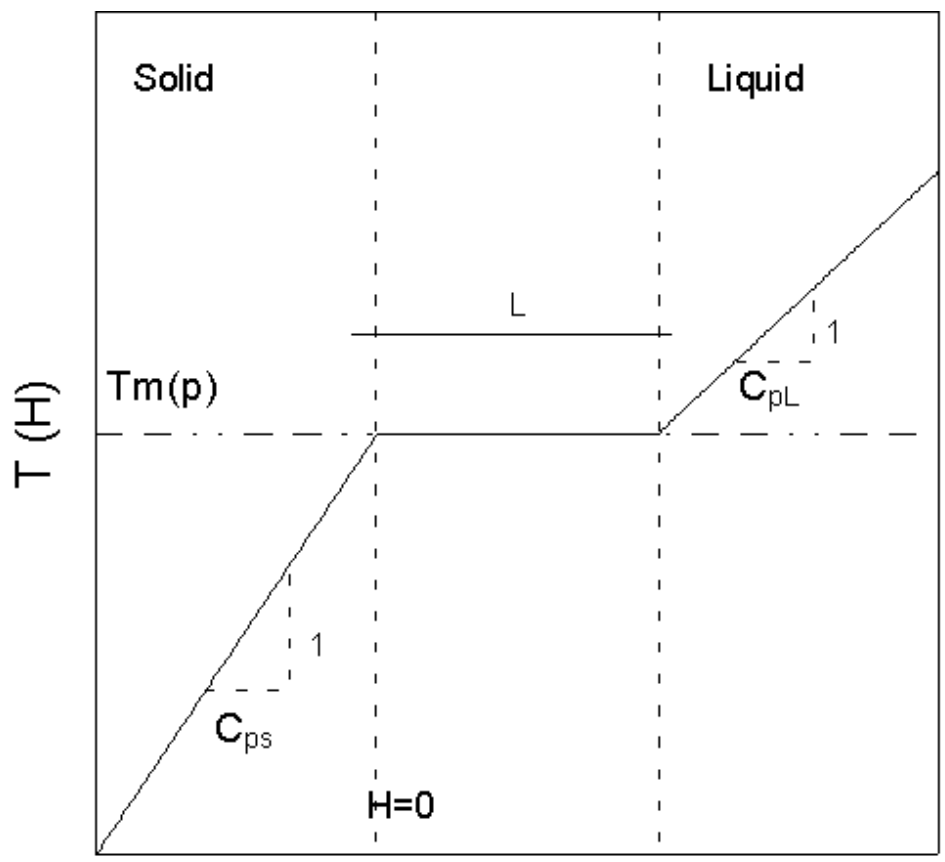

$\mathrm{H}$

Figure 4. Temperature-enthalpy diagram 

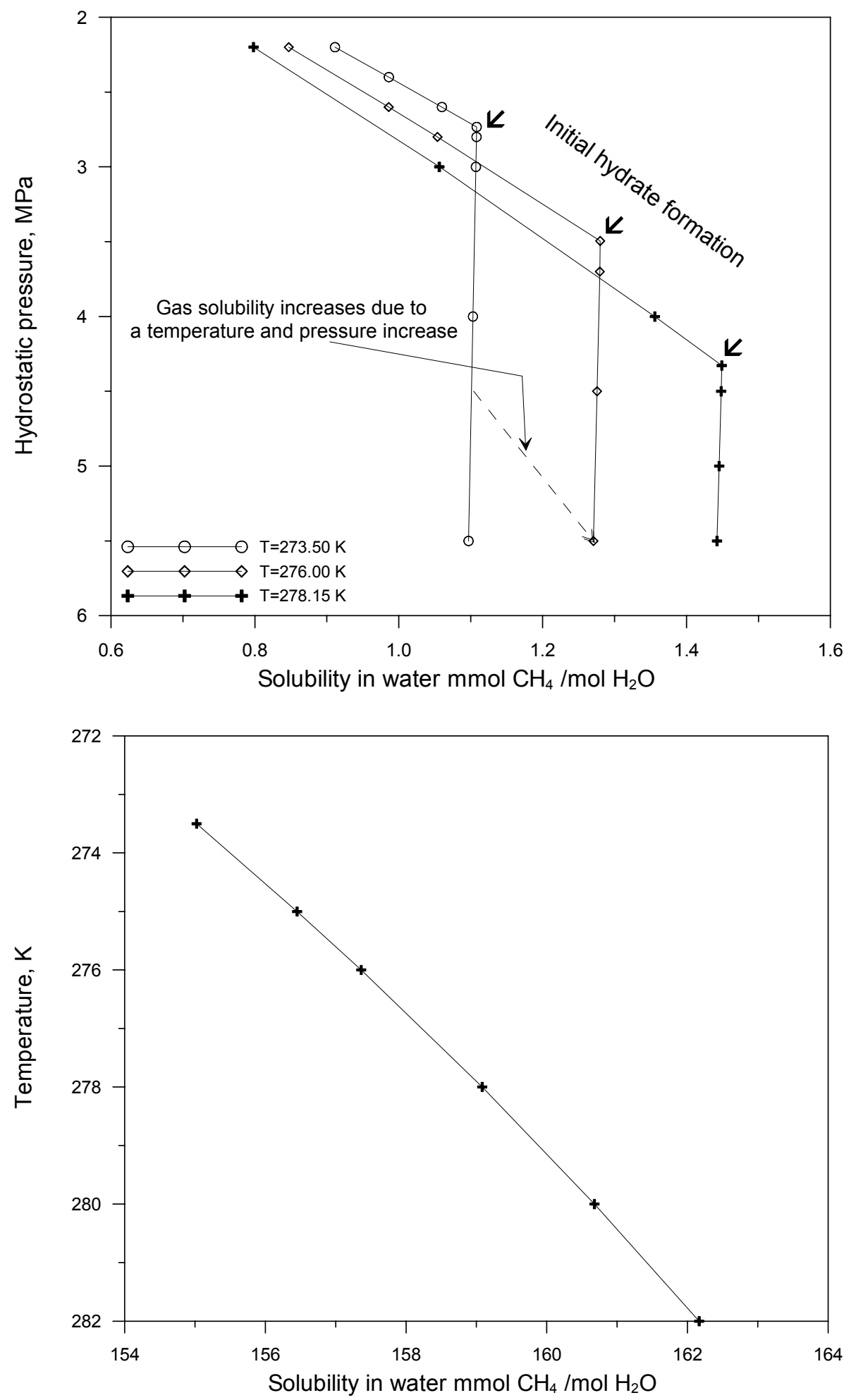

Figure 5. a) Solubility of methane in water Vs. temperatures and pressure. The inflection point corresponds to the equilibrium hydrate pressure. The solubility below the point of inflection is for the two-phase liquid-gas system, the point of inflection is for the three phase hydrate-liquid-gas system and above the point of inflection is for the two phase hydrate-liquid system b) Ratio of methane to water in the hydrate phase. 


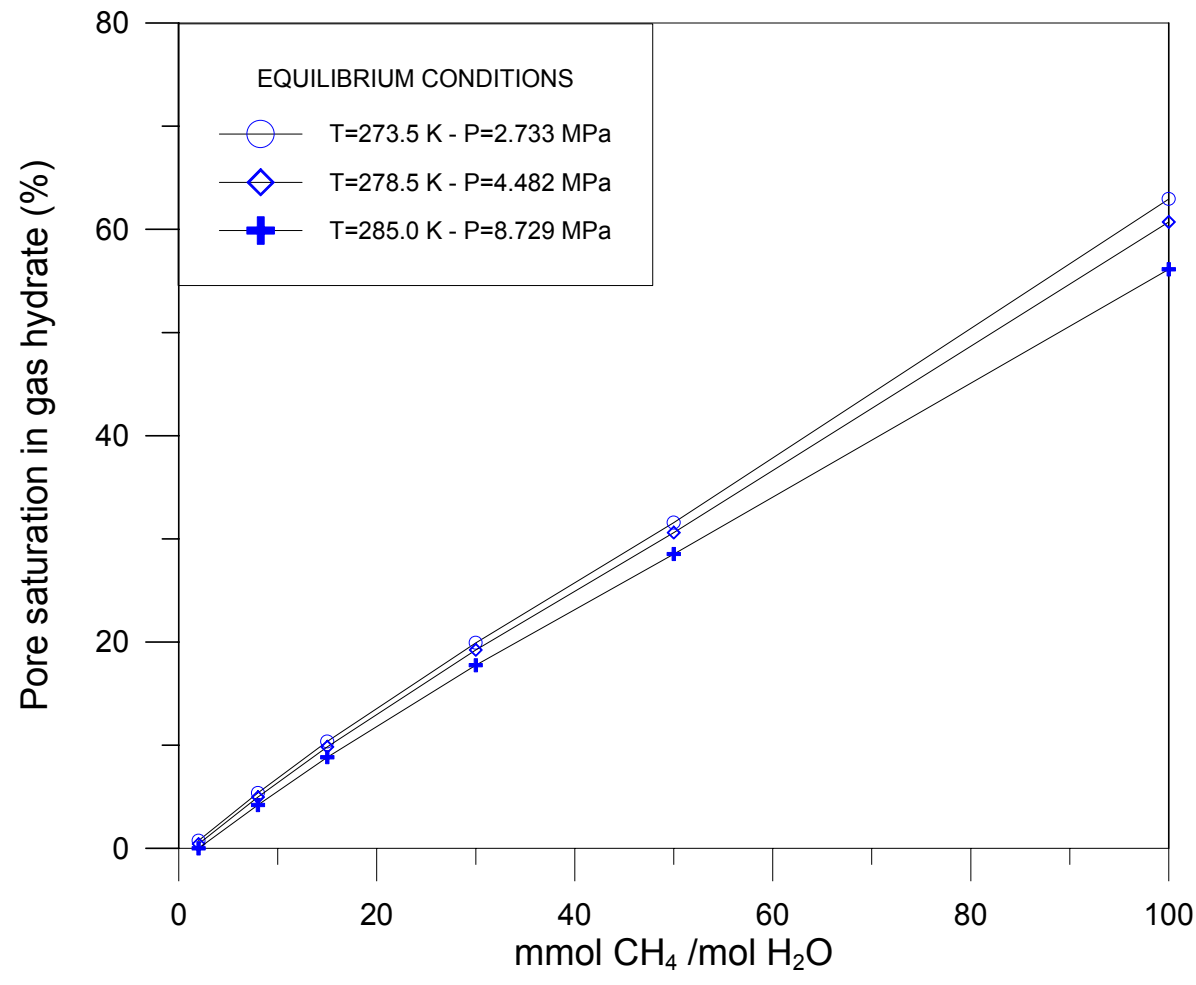

Figure 6. Pore saturation in gas hydrate as a function of temperature and pressure. 


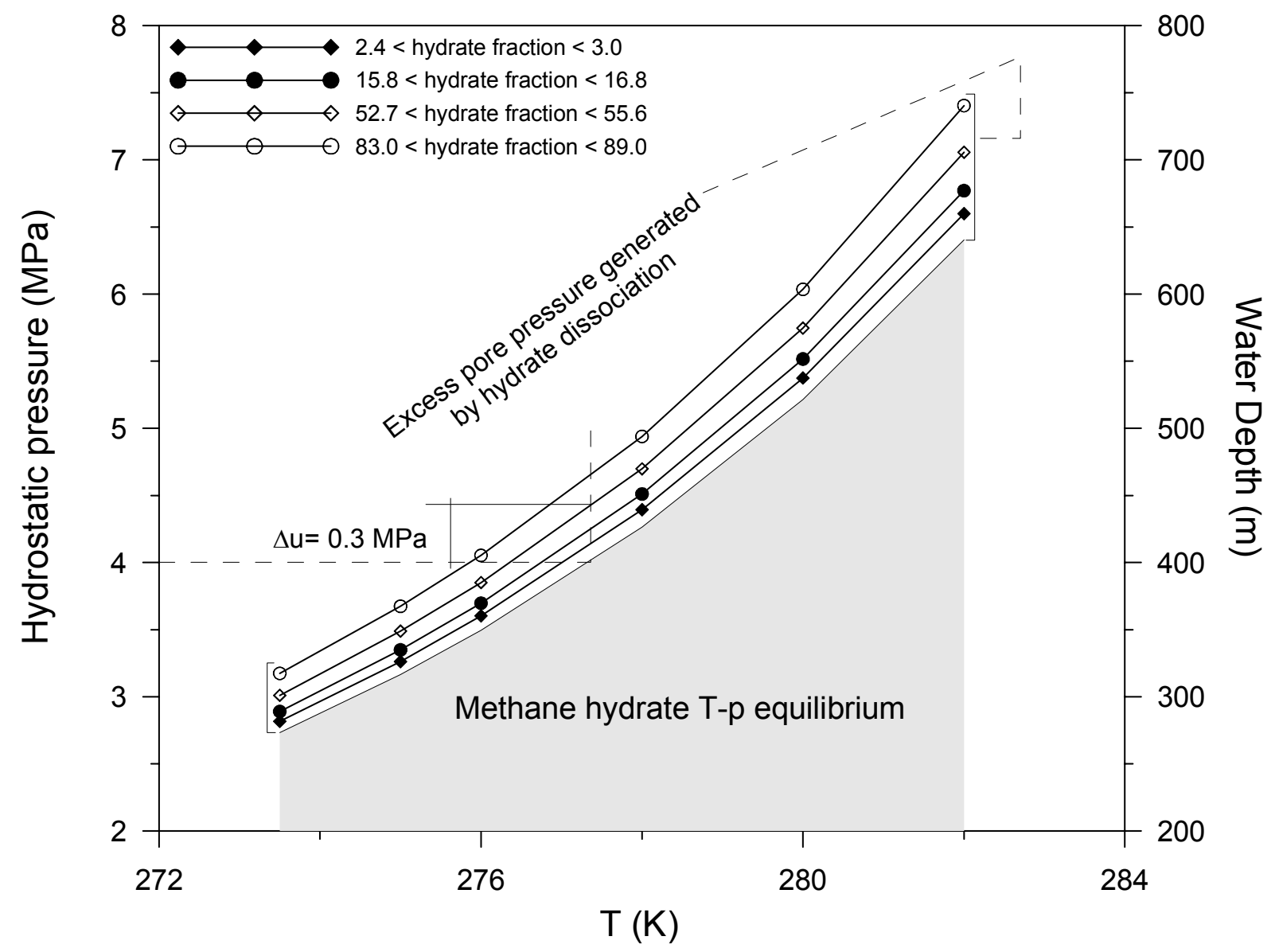

Figure 7. Excess pore pressure generated by the melting of methane hydrate at different gas hydrate pore saturation. For a hydrostatic pressure of $4 \mathrm{MPa}$, the melting of the methane hydrate will generate around 0.3 MPa for an initial hydrate fraction of $52 \%$. 

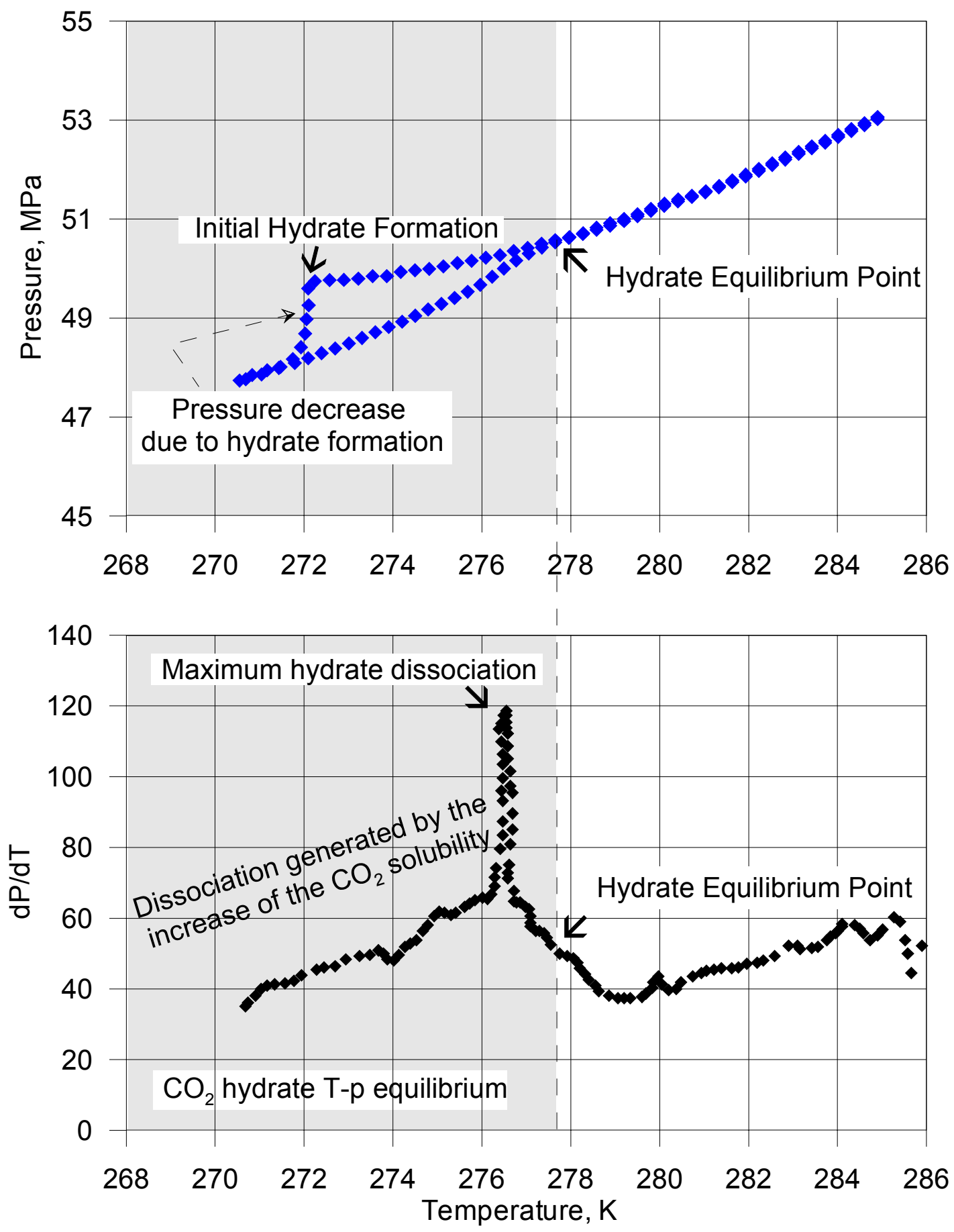

Figure 8. a) Pressure vs Temperature history of an experiment in which hydrates were formed and decomposed in a single-phase solution of dissolved $\mathrm{CO}_{2}$ in water. b) $\mathrm{dP} / \mathrm{dT}$ vs. Temperature for dissociation of $\mathrm{CO} 2$ hydrate in a single-phase solution. (modified from Yi Zhang 2000). 
a)

TGHS: Top of Gas Hydrate Stability zone

which prevents the hydrate

formation over the first meters

Hydrate occurrence Zone

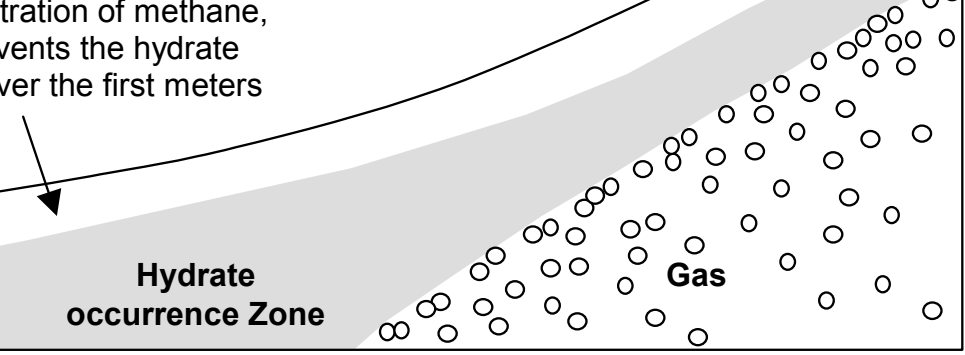

b)

TGHS (for initial temperature and initial_pressure)

TGHS (for final temperature and final pressure)

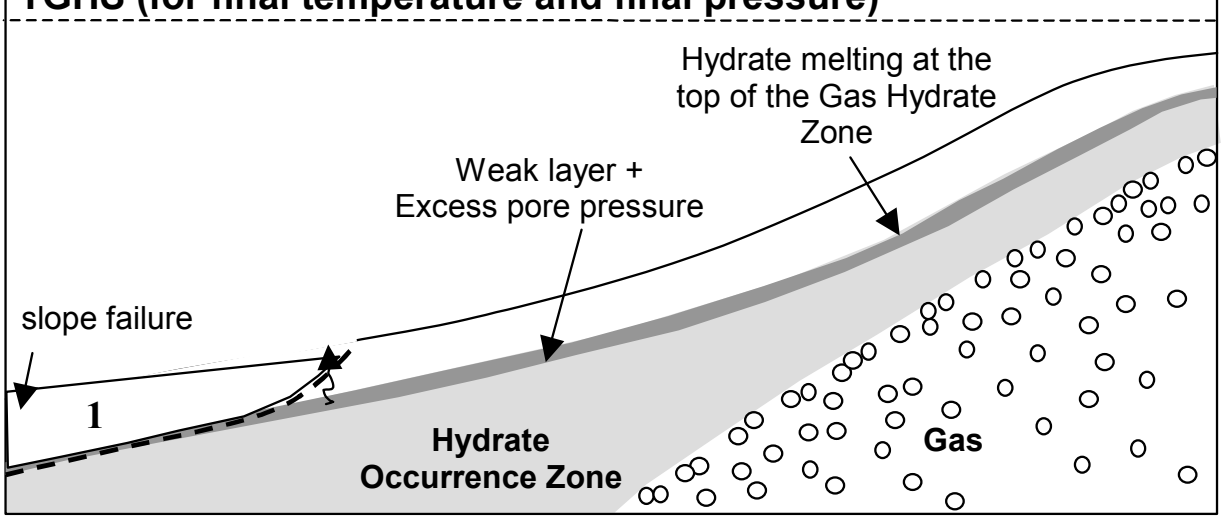

c)

TGHS (for initial temperature and initial pressure)

TGHS (for final temperature and final pressure)

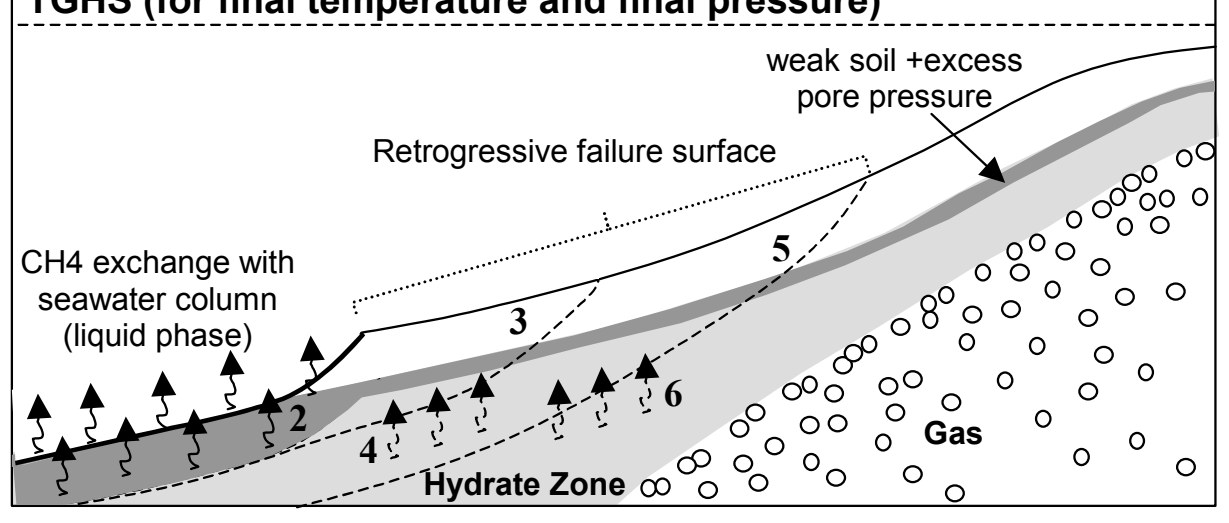

Figure 9. 
Figure 9. Sketch of a retrogressive failure surface generated by the hydrate decomposition due to gas solubility in the hydrate stability zone. a) the low concentration of the methane over the first meters prevent the formation of the methane hydrate. The considered slope is within the hydrate stability zone b) due to a temperature and pressure increase the TGHS will move done. The considered slope remains in the gas hydrate stability zone. The temperature and pressure increase leads to an increase of the methane solubility and consequently the hydrate decomposed in a single-phase solution. The hydrate decomposition generates an excess pore pressure and a weak soil for sufficient hydrate concentrations. The first slope failure occurs in the lower part of the slope c) after the first slope failure, the gas exchange with the water column (2) will remould the upper part of the sediment leading to a second slope failure (3). The mechanism of gas exchange with the water column $(4,6)$, remoulding of the upper sediment layer and inducing slope failures $(3,5)$ will retrograde. 


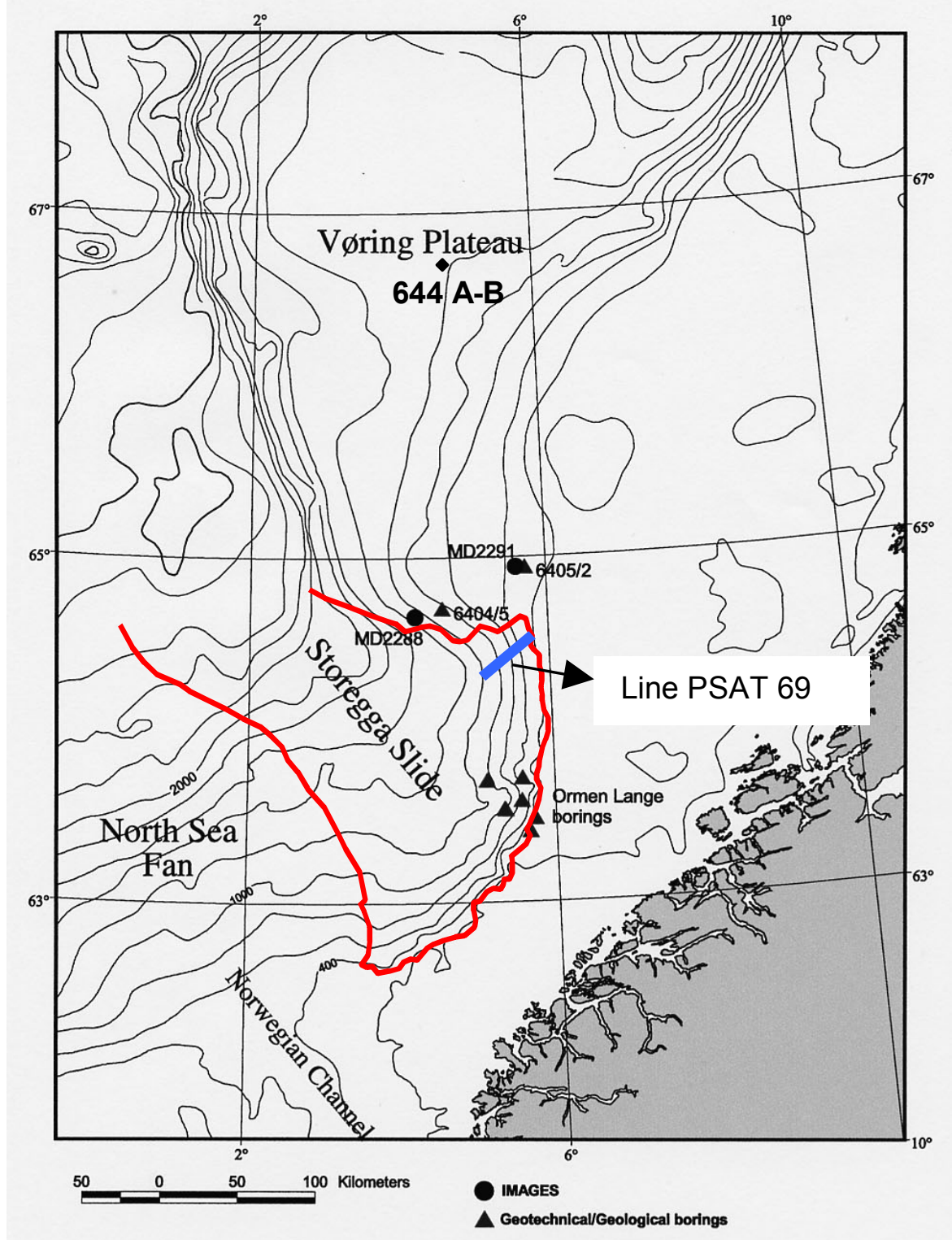

Figure 10. Bathymetry of the Storegga Slide including ODP drill sites, core location (MD992288) and the PSAT69 line position. 

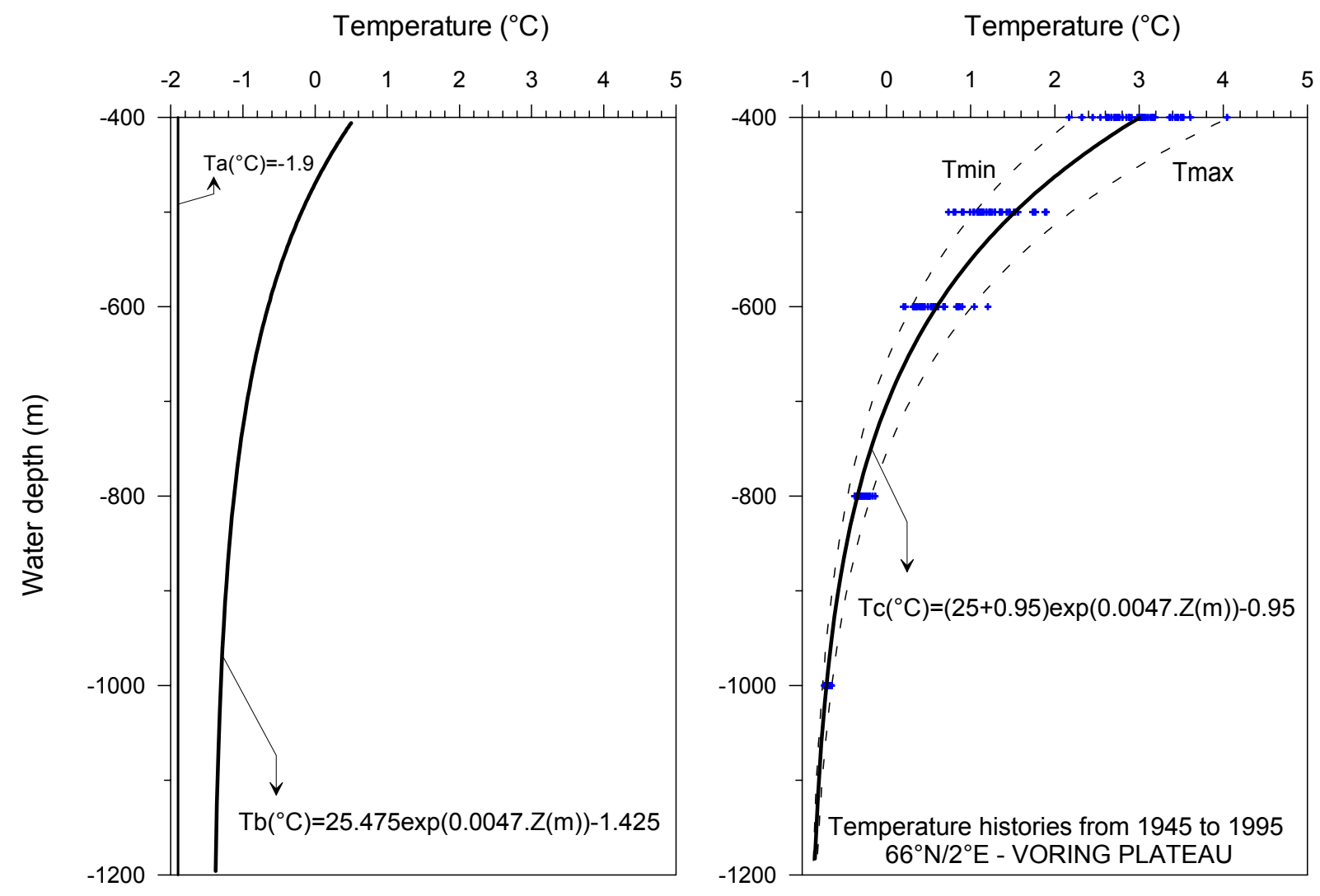

Figure 11. Temperature history versus water depth: a) from $12 \mathrm{ky}$ to $10 \mathrm{ky}$, the temperature was considered constant and equal to $-1.9^{\circ} \mathrm{C} \mathrm{b}$ ) From $10 \mathrm{ky}$ to $9 \mathrm{ky}$, the temperature profile (Tb) was taken as the mean curve of the temperature of $-1.9^{\circ} \mathrm{C}$ and the present temperature profile c) Since 9 ky the temperature was taken equal to the present mean curve profile presented in Figure 11-b 


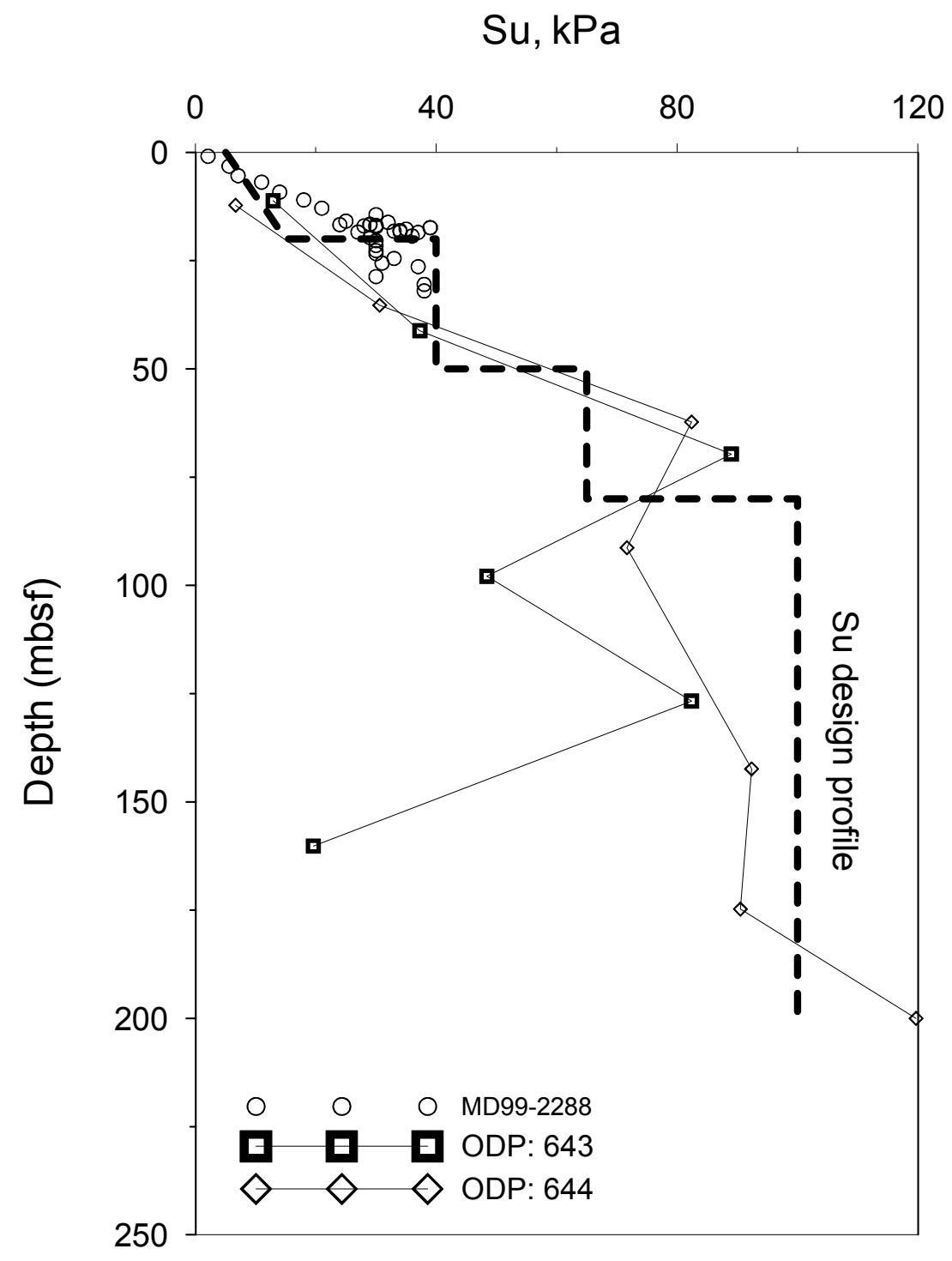

Figure 12. Undrained shear strength design profile based on data from core MD99-2288 and ODP site 644. 

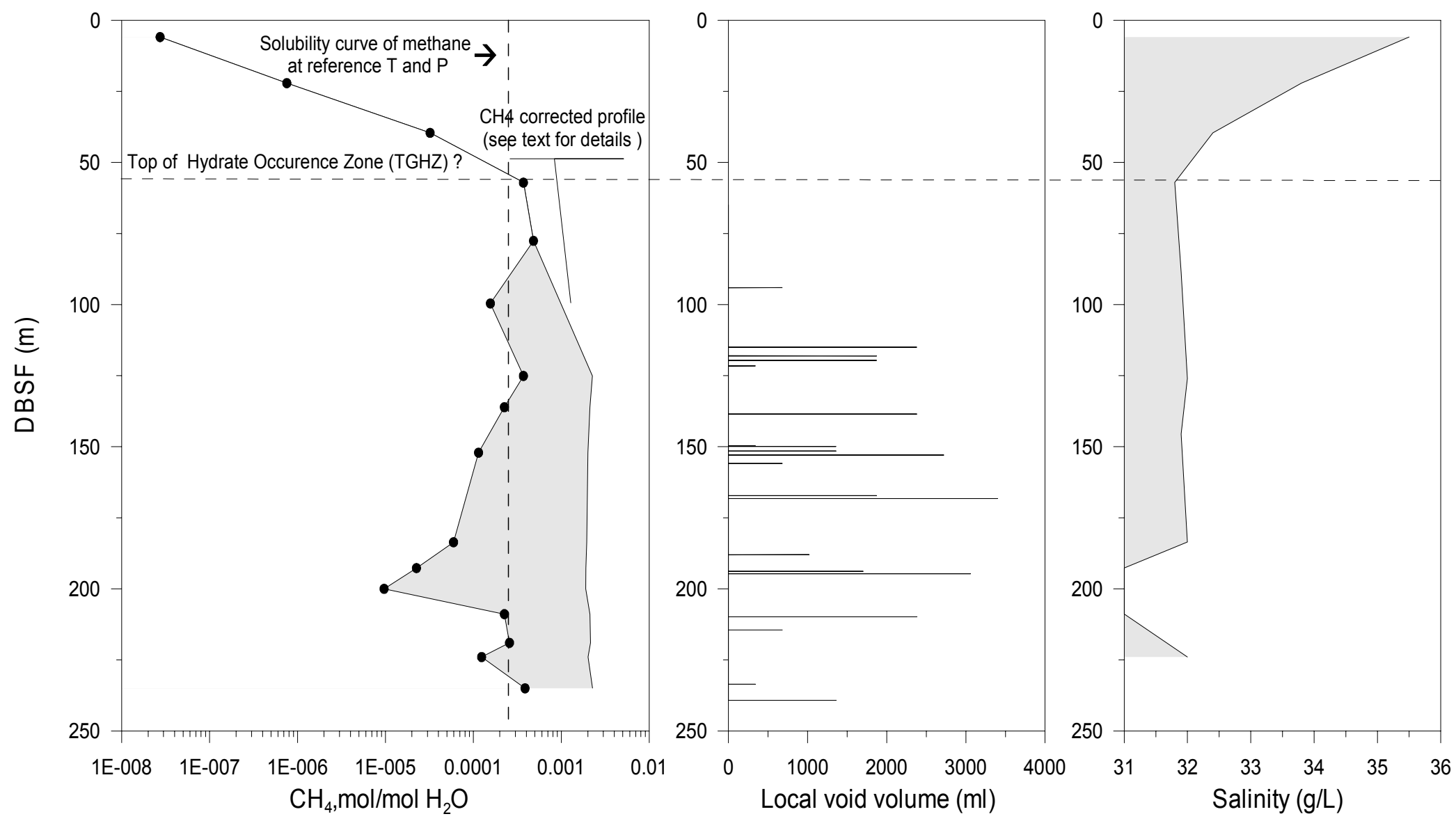

Figure 13. a) Methane concentration vs depth at site 644 from Kvenvolden et al. (1989) and corrected methane profile proposed in this work b) Local void volume form in the cores and c) salinity vs depth at site 644 . 


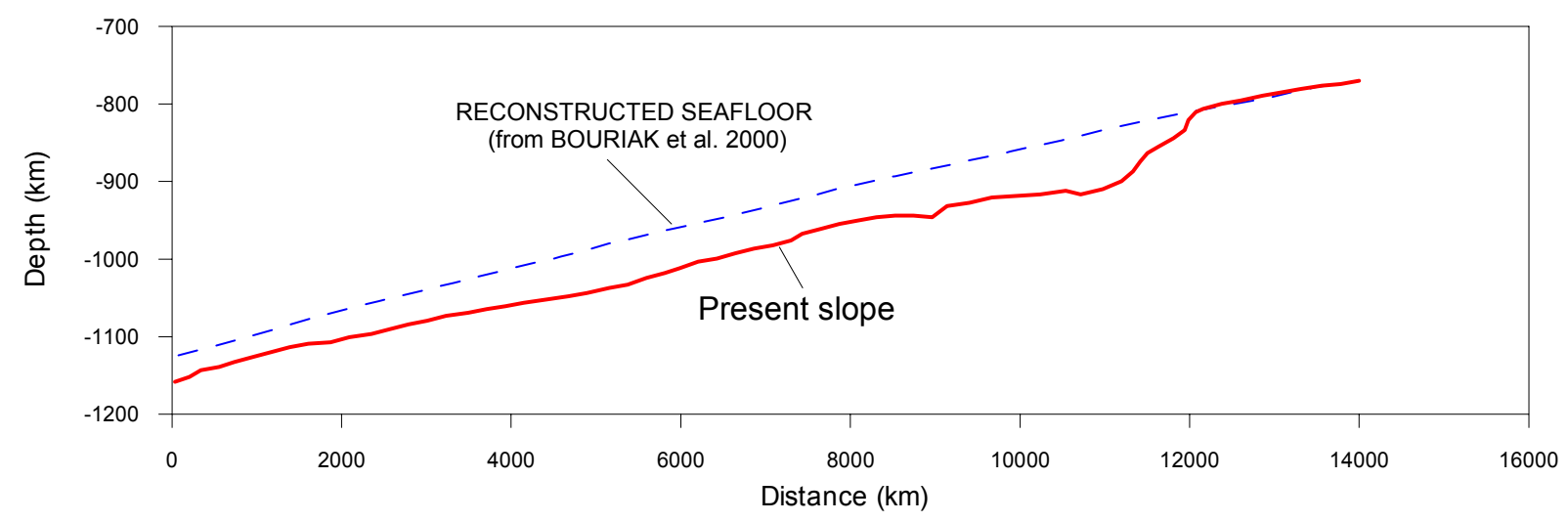

Figure 14. Reconstruction of the seafloor topography over the line PSAT69 (from Bouriak et al. 2000) (for location, see Figure 10). 

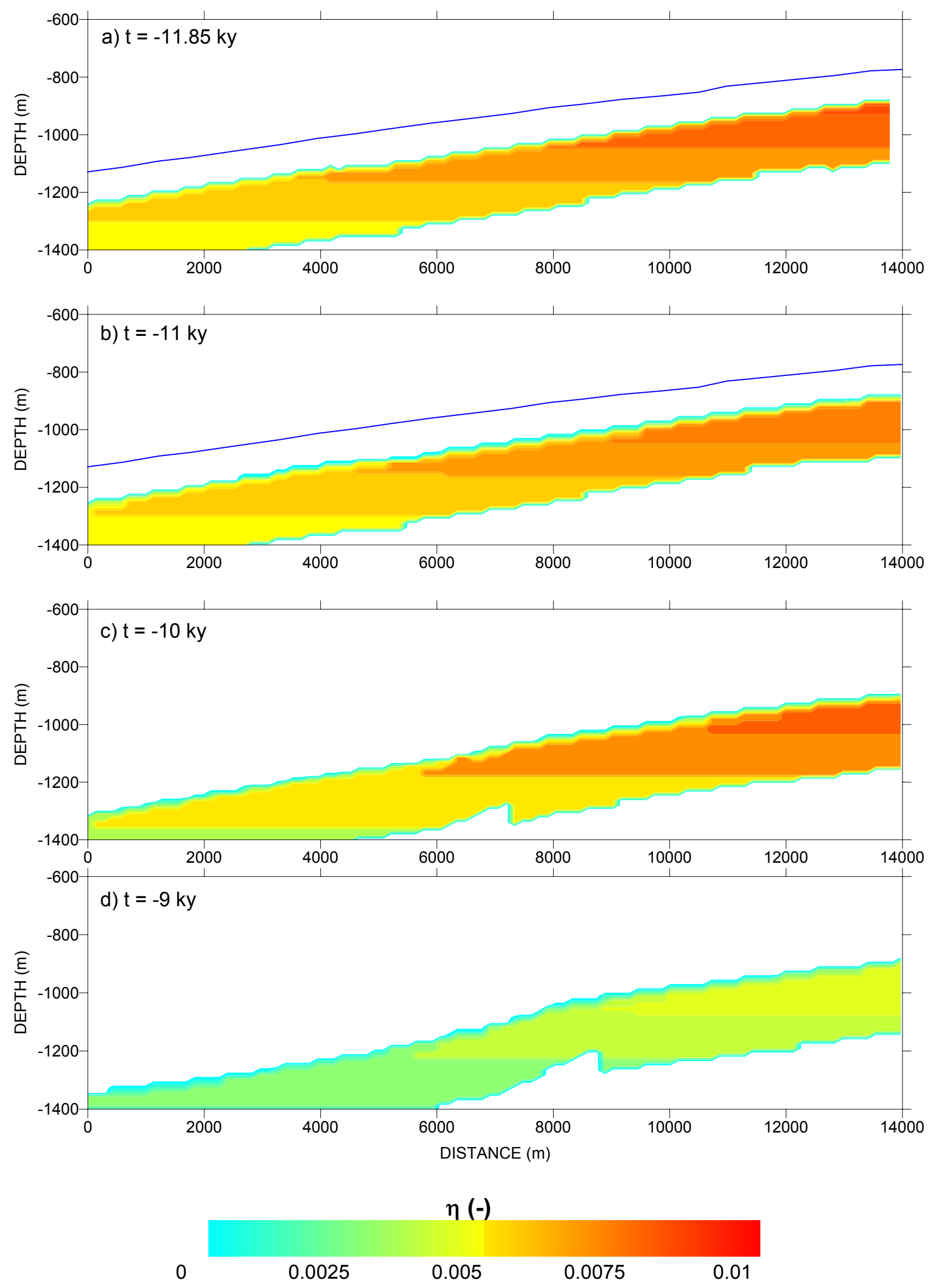

Figure 15. Hydrate fraction over the reconstructed slope as a function of time. For the $10 \mathrm{ky}$ and $9 \mathrm{ky}$ graphs, the seafloor was update from the calculation of the slope stability under drained conditions. 

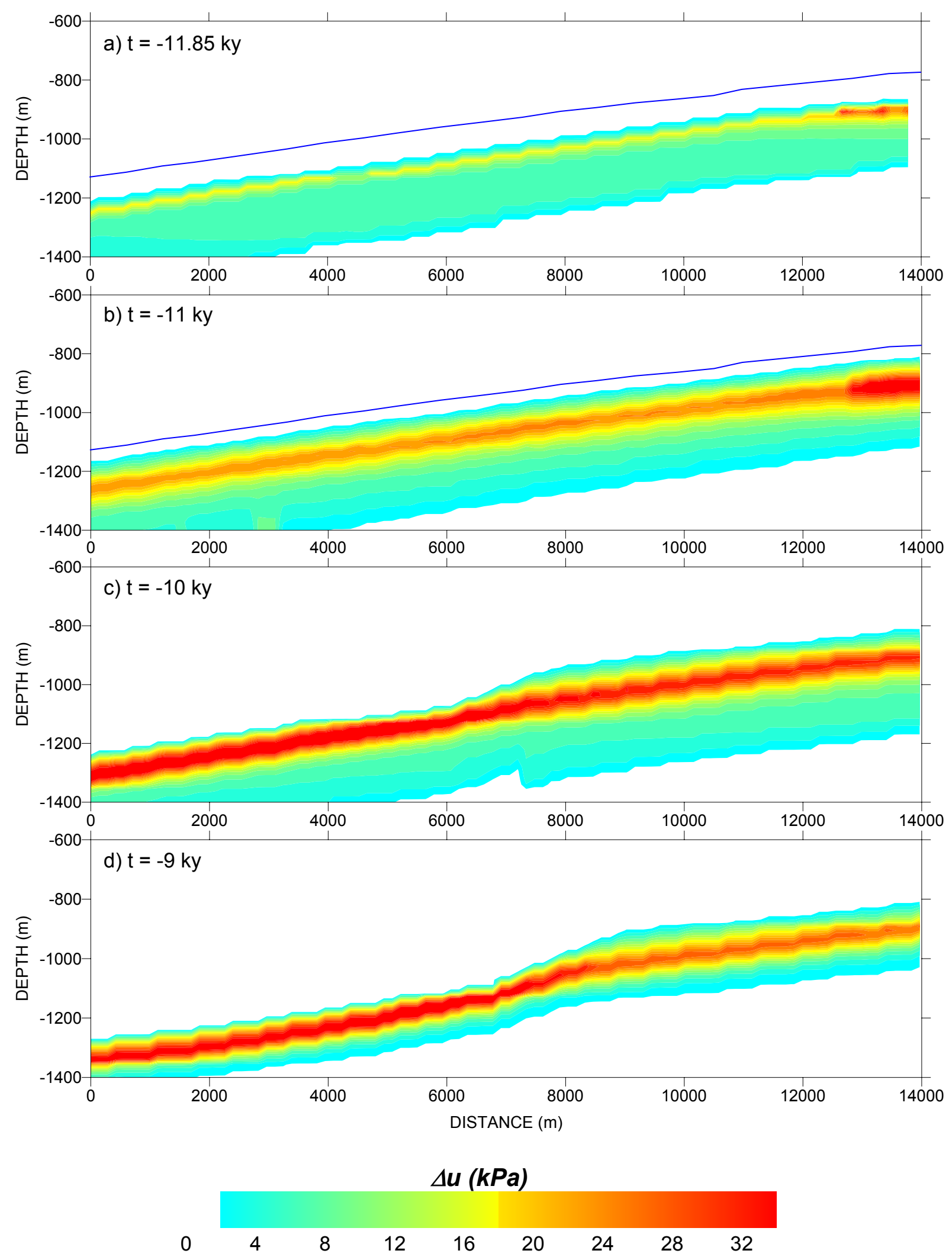

Figure 16. Distribution of the excess pore pressure over the reconstructed slope as a function of time. For the $10 \mathrm{ky}$ and $9 \mathrm{ky}$ graphs, the seafloor was update from the calculation of the slope stability under drained conditions. 

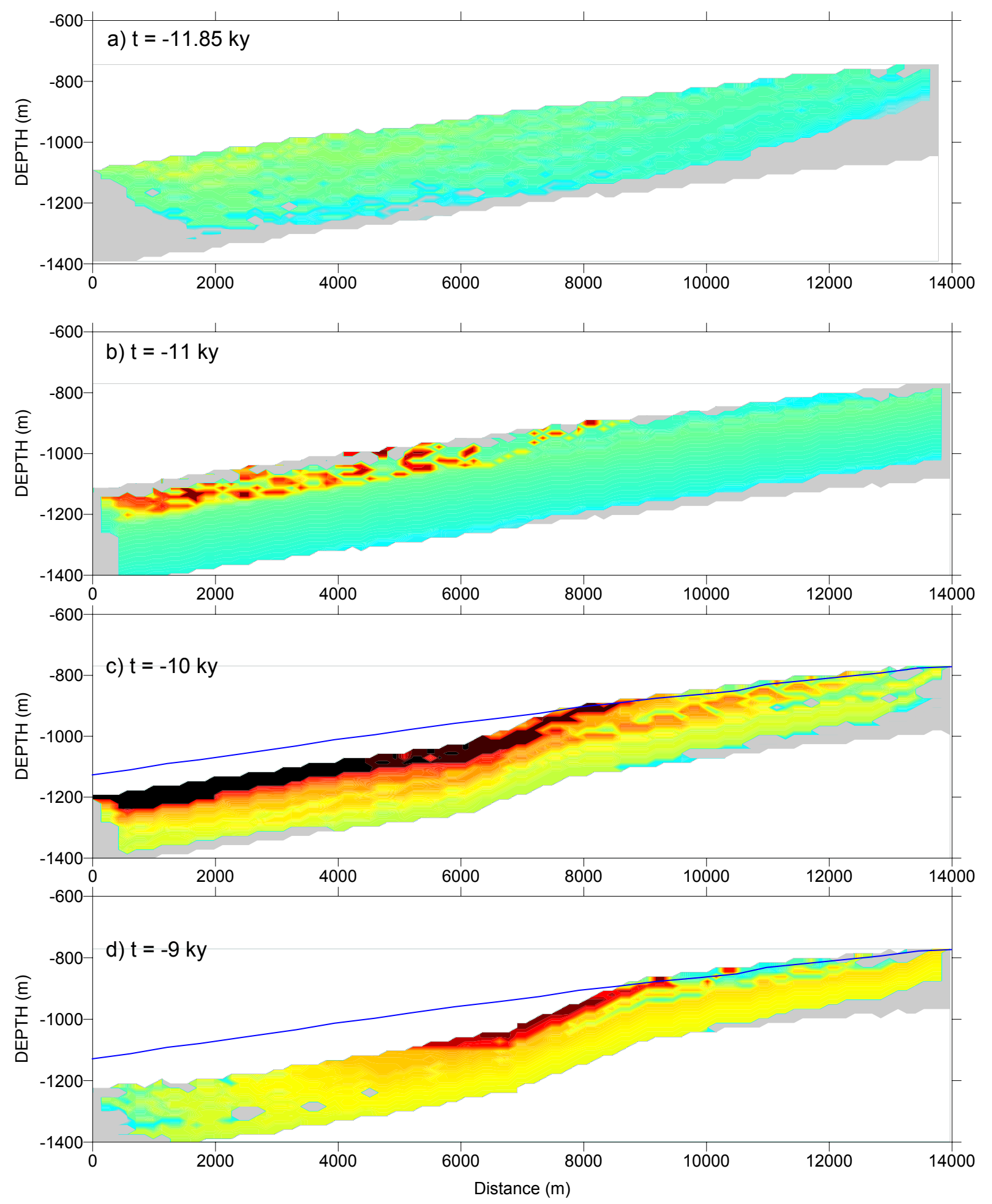

FOS (-)

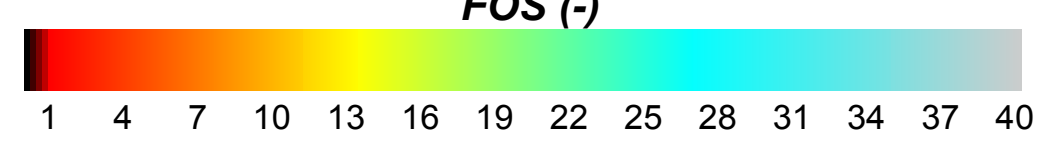

Figure 17. Factor Of Safety (FOS) under drained conditions over the reconstructed slope as a function of time. 